\title{
Monitoring Human Copper/Zinc Superoxide Dismutase Misfolding/Aggregation in Mammalian Cells
}

\author{
A Thesis \\ Presented to \\ the faculty of the School of Engineering and Applied Science \\ University of Virginia
}

In Partial Fulfillment

of the requirements for the Degree

Masters of Science (Chemical Engineering)

by

Simpson Emmanuel Gregoire

May 2012 


\begin{abstract}
$\underline{\text { Abstract }}$
Protein misfolding and aggregation play important roles in many processes in living organisms. These include pathological protein aggregation in neurodegenerative diseases and biopharmaceutical protein aggregation during production in mammalian cells. Despite obvious benefits, non-invasive quantitative assays for protein misfolding and mammalian cell aggregation have not been extensively exploited. In order to develop a simple non-invasive assay for protein misfolding and aggregation in mammalian cells, the folding reporter green fluorescent protein (GFP) system, originally developed for bacterial cells, was evaluated. As a folding reporter, GFP was fused to the C-terminus of a panel of human copper/zinc superoxide dismutase (SOD1) mutants with varying misfolding/aggregation propensities. Flow cytometric analysis of transfected HEK293T and NSC-34 cells revealed that the mean fluorescence intensities of the cells expressing GFP fusion of SOD1 variants exhibit an inverse correlation with the misfolding/aggregation propensities of the four SOD1 variants. These results support the hypothesis that the extent of misfolding/aggregation of a target protein in mammalian cells can be quantitatively estimated by measuring the mean fluorescence intensity of the cells expressing GFP fusion. The assay method developed here will pave the way for investigating protein misfolding/aggregation in mammalian cells.
\end{abstract}




\section{Acknowledgements}

I would like to thank the following people:

My research advisor, Professor Inchan Kwon and collaborator Professor Erik Fernandez for their continuing guidance and insight.

Professor Roseanne Ford for serving on my committee.

My labmates from the Kwon group for their support and guidance, particularly

Ed Wong, Shun Zheng, Jacob Irwin and Sung In Lim.

I would like to thank for summer undergraduate research assistants Yomi Famuyiwa and Arvind Rachamadugu for their efforts.

Finally my friends and family, specifically my parents, Nina and Simpson, and my siblings, Nadine and Brendon, and my best friend, Serena, for their continuing love and support. 


\section{Table of Contents}

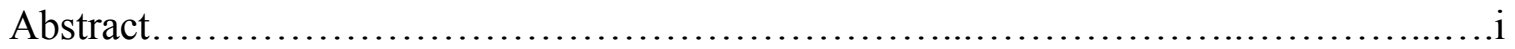

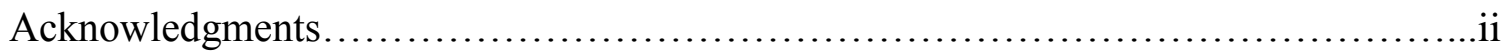

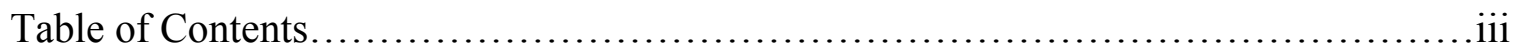

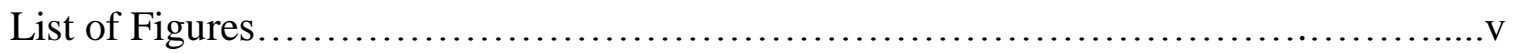

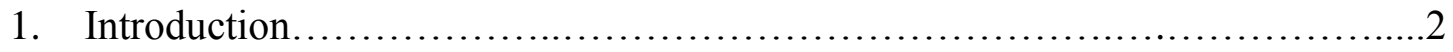

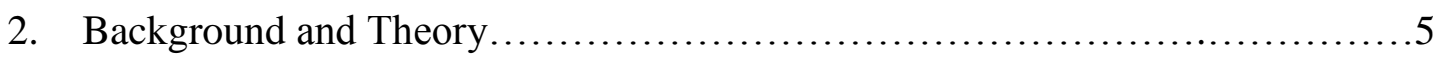

2.1 Monitoring Protein Misfolding/Aggregation Using Fluorescent Reporter

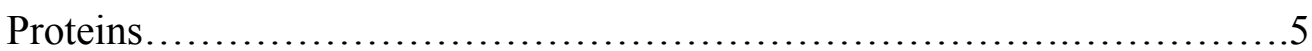

2.1.1 GFP ...................................................

2.1.2 ZsGreen................................................. 8

2.2 Monitoring Protein Misfolding/Aggregation Using Selective Pressures..........8

2.2.1 $\beta$-Lactamase............................................... 8

2.2.2 Expression of Soluble Proteins by Random Incremental Truncation $($ ESPRIT) $\ldots \ldots \ldots \ldots \ldots \ldots \ldots \ldots \ldots \ldots \ldots \ldots \ldots \ldots$

2.2.3 Murine Dihydrofolate Reductase (mDHFR) .................10

2.3 Choice of Model Protein...................................................11

3 Research Scope and Objectives ..............................................13

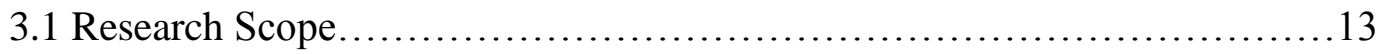

3.2 Research Objectives................................................. 14

4 Materials and Methods........................................................... 16 
4.1 Materials........................................................ 16

4.2 Methods.......................................................... 16

4.2.1 Construction of Expression Vectors....................16

4.2.2 Transfection of HEK293T and NSC-34 Cells................16

4.2.3 Fluorescence Microscopy .............................18

4.2.4 Flow Cytometric Analysis of Cellular Fluorescence .........18

4.2.5 Dot Blotting ....................................... 19

5 Results and Discussion................................................. 20

5.1 Fluorescence Microscopic Observation of Transfected HEK293T Cells Expressing SOD1 Variants.......................................20

5.2 Flow Cytometric Analysis of Transfected HEK293T Cells Expressing SOD1

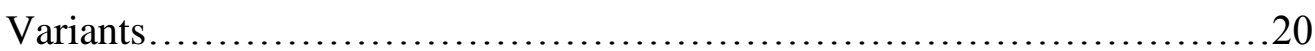

5.3 Aggregate Formation of SOD1 ${ }^{\mathrm{A} 4 \mathrm{~V}}$ Variants in Transfected HEK293T Cells 28 5.4 Comparison of the Cellular Fluorescence of Transfected NSC-34 and HEK293T Cells Expressing SOD1 Variants. ........................... 32

5.5 Comparison of the CMV and Ubiquitin-C Promoters........................35

6 Conclusions........................................................... 40

7 Recommendations...........................................................

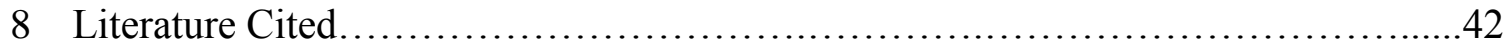




\section{List of Figures}

Figure 5.1: Fluorescence microscopy images of the transfected HEK293T cells expressing SOD1 variants fused to EGFP. Images of transfected HEK293T cells expressing EGFP fusion of SOD $1^{\mathrm{WT}}, \mathrm{SOD} 1^{\mathrm{A} 4 \mathrm{VC} 111 \mathrm{~S}}, \mathrm{SOD} 1^{\mathrm{A} 4 \mathrm{~V}}$, and SOD1 ${ }^{\mathrm{A} 4 \mathrm{~V} / \mathrm{C} 57 \mathrm{~S}}$ taken at two days post-transfection. Transfection efficiency for each SOD1 variant was determined by calculating the percentage of GFP positive cells out of total cells analyzed using flow cytometry. Values represent means \pm standard deviation $(n=3) \ldots \ldots \ldots . .21$

Figure 5.2: Comparison of the cellular fluorescence intensities and expression levels of EGFP fusion of SOD1 variants. (A) Time course of fluorescence intensities of the transfected HEK293T cells expressing EGFP fusion of SOD1 variants. Fluorescence intensities of untransfected cells (day 0) and transfected cells expressing EGFP fusion of four SOD1 variants $\left(\mathrm{SOD} 1^{\mathrm{WT}}, \mathrm{SOD} 1^{\mathrm{A} 4 \mathrm{VC} 111 \mathrm{~S}}, \mathrm{SOD}^{\mathrm{A} 4 \mathrm{~V}}\right.$, and $\mathrm{SOD} 1^{\mathrm{A} 4 \mathrm{~V} / \mathrm{C} 57 \mathrm{~S}}$ ) at day 1 and 2 were determined by flow cytometry. Fluorescence intensities of cells expressing $\mathrm{SOD}^{\mathrm{A} 4 \mathrm{~V} / \mathrm{C} 111 \mathrm{~S}}$ or SOD1 $1^{\mathrm{A} 4 \mathrm{~V} / \mathrm{C} 57 \mathrm{~S}}$ were significantly higher $(* ; \mathrm{P}<0.05)$ or lower $(* * ; \mathrm{P}<$ 0.001) than those of cells expressing $\mathrm{SOD}^{\mathrm{A} 4 \mathrm{~V}}$, respectively, at days 1 and 2 posttransfection. Values and error bars represent mean cellular fluorescence and standard deviations, respectively $(\mathrm{n}=3)$. Two-sided Student's t-tests were applied to the data. (B) Dot-blot images of the transited cell lysates of EGFP fusion of SOD1 ${ }^{\mathrm{WT}}$ and SOD1 ${ }^{\mathrm{A} 4 \mathrm{~V}}$. $\alpha$-tubulin levels of SOD $1^{\mathrm{WT}}$ and SOD $1^{\mathrm{A} 4 \mathrm{~V}}$ determined using anti- $\alpha$ tubulin monoclonal antibody were compared to ensure loading of similar amount of protein samples. Expression levels of EGFP fusion of SOD1 ${ }^{\mathrm{WT}}$ and $\mathrm{SOD} 1^{\mathrm{A} 4 \mathrm{~V}}$ were compared using antiGFP polyclonal antibody. (C) Comparison of the mean cellular fluorescence of 
HEK293T cells expressing SOD1 variants that were transfected at two separate days. At two days post-transfection, cellular fluorescence of transfected HEK293T cells expressing EGFP fusion of SOD1 variants $\left(\mathrm{SOD} 1^{\mathrm{WT}}, \mathrm{SOD} 1^{\mathrm{A} 4 \mathrm{VC1} 11 \mathrm{~S}}, \mathrm{SOD} 1^{\mathrm{A} 4 \mathrm{~V}}\right.$, and $\mathrm{SOD}^{\mathrm{A} 4 \mathrm{~V} / \mathrm{C} 57 \mathrm{~S}}$ ) was determined by flow cytometry. The data were fitted to a straight line $\left(\mathrm{R}^{2}=0.99\right) . \quad($ a.u. $=$ arbitrary unit $)$

Figure 5.3. Mean cellular fluorescence intensities of transfected HEK293T cells coexpressing split GFP fragments fused to $\mathrm{SOD} 1^{\mathrm{WT}}$ or $\mathrm{SOD} 1^{\mathrm{A} 4 \mathrm{~V}}$. In order to achieve split GFP complementation, both pCMV-mGFP_1-10 and pCMV-mGFP_Cterm_S11 plasmids encoding large and small GFP fragment gene respectively, which are originally developed by Waldo group, were obtained from Theranostech, Inc. (Albuquerque, NM) (Cabantous et al, 2005b; Cabantous \& Waldo, 2006). PCR-amplified SOD1 ${ }^{\mathrm{WT}}$ and $\mathrm{SOD}^{\mathrm{A} 4 \mathrm{~V}}$ genes were inserted between Nhe I and BamHI restriction sites of pCMVmGFP_Cterm_S11 to generate $\mathrm{pCMV} \_S O D 1^{\mathrm{WT}}-\mathrm{mGFP} \_\mathrm{S} 11$ and ${ }^{\mathrm{pCMV}-S O D} 1^{\mathrm{A} 4 \mathrm{~V}}$ mGFP_S11, respectively. HEK293T cells were co-transfected with pCMV-mGFP_1-10 and either pCMV_SOD1 ${ }^{\mathrm{WT}}$-mGFP_S11 or pCMV-SOD $1^{\mathrm{A} 4 \mathrm{~V}}$-mGFP_S11 plasmid. Mean cellular fluorescence intensities of the transfected HEK293T cells were determined by flow cytometry at two days post-transfection. Values indicate the mean cellular fluorescence intensities and standard deviations $(n=3)$.

Figure 5.4: Aggregate formation of $\mathrm{SOD} 1^{\mathrm{A} 4 \mathrm{~V}}$ in transfected HEK293T cells. (A) Fluorescence microscopic images of the transfected HEK293T cells expressing EGFP fusion of SOD1 variants. Images of transfected HEK293T cells expressing EGFP fusion 
of SOD $1^{\mathrm{WT}}$ and SOD $1^{\mathrm{A} 4 \mathrm{~V}}$ were taken at two days post-transfection. SOD $1^{\mathrm{WT}}$-EGFP is almost evenly distributed in the cytosol but SOD $1^{\mathrm{A} 4 \mathrm{~V}}$-EGFP forms aggregates. Arrows indicate the aggregates within the cell. (B) The percentage of transfected HEK293T cells exhibiting SOD1 aggregates. The number of cells exhibiting intracellular SOD1 aggregates was determined by analyzing fluorescence microscopy images of the transfected cells expressing EGFP fusion of four SOD1 variants (SOD1 ${ }^{\mathrm{WT}}$, $\mathrm{SOD}^{\mathrm{A} 4 \mathrm{VC} 111 \mathrm{~S}}, \mathrm{SOD}^{\mathrm{A} 4 \mathrm{~V}}$, and $\mathrm{SOD} 1^{\mathrm{A} 4 \mathrm{~V} / \mathrm{C} 57 \mathrm{~S}}$ ) at day two post-transfection. The percentage of aggregates-found cells expressing SOD1 $1^{\mathrm{A} 4 \mathrm{~V} / \mathrm{C} 111 \mathrm{~S}}$ was significantly lower $\left(^{*} ; \mathrm{P}<0.05\right)$ compared to that of SOD $1^{\mathrm{A} 4 \mathrm{~V}}$. Values and error bars represent mean and standard deviations, respectively $(\mathrm{n}=3)$. Two-sided Student's t-tests were applied to the data 31

Figure 5.5. Comparison of the orders of fluorescence intensities of transfected HEK293T and NSC-34 cells expressing EGFP fusion of SOD1 variants Fluorescence intensities of the transfected NSC-34 cells expressing EGFP fusion of SOD1 variants (SOD1 ${ }^{\mathrm{WT}}, \mathrm{SOD}^{\mathrm{A} 4 \mathrm{VC} 111 \mathrm{~S}}, \mathrm{SOD}^{\mathrm{A} 4 \mathrm{~V}}$, and $\left.\mathrm{SOD} 1^{\mathrm{A} 4 \mathrm{~V} / \mathrm{C} 57 \mathrm{~S}}\right)$ at two days posttransfection were determined by flow cytometry. Fluorescence intensities of cells expressing $\mathrm{SOD} 1^{\mathrm{A} 4 \mathrm{~V} / \mathrm{C} 111 \mathrm{~S}}$ or $\mathrm{SOD} 1^{\mathrm{A} 4 \mathrm{~V} / \mathrm{C} 57 \mathrm{~S}}$ were significantly higher $(* ; \mathrm{P}<0.05)$ or lower $(* * ; \mathrm{P}<0.01)$ than those of cells expressing $\mathrm{SOD}^{\mathrm{A4V}}$. Values and error bars represent mean cellular fluorescence and standard deviations, respectively $(\mathrm{n}=3)$. Twosided Student's t-tests were applied to the data. (a.u. = arbitrary unit) (B) Comparison of the cellular fluorescence of the transfected HEK293T at day two and NSC-34 cells at day three post-transfection. The cellular fluorescence of transfected HEK293T and NSC-34 
cells expressing EGFP fusion of SOD1 variants $\left(\mathrm{SOD} 1^{\mathrm{WT}}, \mathrm{SOD}^{\mathrm{A4VC} 111 \mathrm{~S}}, \mathrm{SOD} 1^{\mathrm{A4V}}\right.$, and $\mathrm{SOD} 1^{\mathrm{A} 4 \mathrm{~V} / \mathrm{C} 57 \mathrm{~S}}$ ) was determined by flow cytometry. The data were fitted to a straight line $\left(\mathrm{R}^{2}=0.98\right) . \quad \mathrm{FL}\left(\mathrm{SOD} 1^{\mathrm{X}}\right) / \mathrm{FL}\left(\mathrm{SOD} 1^{\mathrm{WT}}\right)$ indicates the ratio of fluorescence intensity of cells expressing a SOD1 variant $\left(\mathrm{SOD}^{\mathrm{X}}\right)$ over the fluorescence intensity of cells

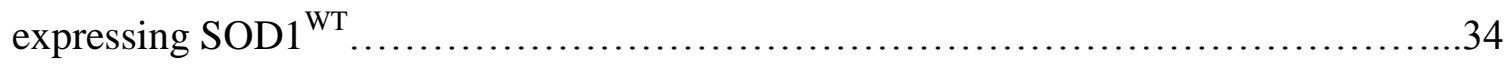

Figure 5.6. Comparison of CMV and Ubc promoter activities for the fluorescence intensities of transfected HEK293T cells expressing EGFP fusion of SOD1 variants. Cellular fluorescence of HEK293Tcells expressing EGFP fusion of SOD1 ${ }^{\text {WT }}$ and $\mathrm{SOD}^{\mathrm{A} 4 \mathrm{~V}}$ under the control of either CMV or Ubc promoter was determined by flow cytometry. Values and error bars represent mean cellular fluorescence and standard deviations, respectively $(\mathrm{n}=3)$. (a.u. $=$ arbitrary unit).

Figure 5.7. Mean cellular fluorescence intensities of transfected HEK293T cells coexpressing firefly luciferase (Luc) and either SOD $1{ }^{\mathrm{WT}}$-EGFP or SOD $1{ }^{\mathrm{A} 4 \mathrm{~V}}$-EGFP. pAAVLuc plasmid encodes Luc gene under the control of CMV promoter (Jang et al, 2010). HEK293T cells were co-transfected with pAAV-Luc and either pEGFP-N3-SOD1 ${ }^{\text {WT }}$ or pEGFP-N3-SOD1 ${ }^{\mathrm{A} 4 \mathrm{~V}}$ plasmid. Mean cellular fluorescence intensities of the transfected HEK293T cells were determined by flow cytometry at two days post-transfection. Values indicate the mean cellular fluorescence intensities and standard deviations $(\mathrm{n}=$

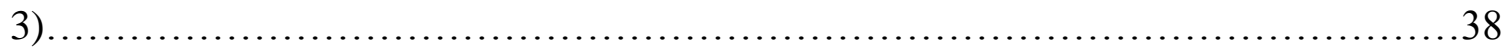




\section{Introduction}

Protein function requires correct folding of a linear chain of natural building blocks, called amino acids, into a complex three-dimensional structure. Unfortunately, harsh cellular environments and other internal factors can alter the three-dimensional structure of the protein, leading to the development of aberrant structures with incorrect or reduced functionalities. The development of these off-pathway structures such as oligomers, fibrillar species and unstructured aggregates are known to alter the cellular environment and may develop a function that is toxic to specific cell types. These atypical species develop an unknown toxic function, leading to the development of many neurological disorders, such as Alzheimer's, Parkinson's, amyotrophic lateral sclerosis, Huntington's, etc. Although it is well understood that the development of the proteinaceous species are associated with the development of these diseases, the mechanism behind how these proteins misfold or aggregate is unclear. In order to develop effective treatments for these diseases, there must be a better understanding of how these proteins misfold or aggregate in certain cellular environments. Furthermore, intracellular aggregate formation and misfolding of biopharmaceuticals, such as $\alpha$ galactosidase, $\alpha$-glucosidase, antithrombine III, and angiopoietin-1 in mammalian cells are often obstacles in achieving high yield production of biopharmaceuticals (Hwang et al, 2011; Ioannou et al, 1992; Ishii et al, 1996; Okumiya et al, 2007; Schröder et al, 2002).

Over the past two decades, researchers have developed a toolbox of protein misfolding/ aggregation monitoring techniques in bacteria, yeast and mammalian cells to help elucidate the misfolding/aggregation process. Since in vitro processes cannot serve 
as a true representation of the cellular environment and emulate true cellular processes, the development of these techniques are vital for understanding the protein folding process. Techniques were developed to determine the spatiotemporal development of aggregates in various subcellular compartments of the cell. Understanding the misfolding/aggregation state of the proteins in living cells gives vital insight on how these aberrant species affect the cell. These in situ techniques, in accordance with other in vitro experiments, can unearth how certain misfolded/aggregated species interact with subcellular compartments in the cell.

Recently, researchers have developed new rapid and efficient assays to monitor protein misfolding/aggregation in cells. Typically, the target protein is fused to a reporter protein, such as a fluorescent protein or an enzyme that confers a resistance to a particular antibiotic. The logic behind such an assay is as follows. A target protein is fused to the Nterminus of the reporter protein via a small linker sequence of amino acids. The folding of the target protein heavily impacts the folding of the reporter protein, leading to changes in phenotype of the fusion protein. The first successful protein aggregation reporter is chloramphenicol acetyltransferase (CAT) (Maxwell et al, 1999). CAT is a homotrimeric protein that retains its enzymatic activity when fused to the C-terminus of another protein. Maxwell et al. reported soluble mutants of an insoluble protein can be identified by the level of chloramphenicol antibiotic resistance of Escherichia coli (E. Coli) when expressing the fusion protein (Maxwell et al, 1999). Aggregation and correct folding were directly correlated with the chloramphenicol antibiotic resistance. A similar assay was created by Wigley et al, tagging a complementary portion of $\beta$-galactosidase ( $\beta$-Gal) to the C-terminus of a target protein. When expressed expressed in E. coli, this 
fusion protein allows for direct quantification of the color intensity of the colonies that are grown on plates containing the larger portion of the $\beta$-Gal protein. These assays were the first in a line of rapid protein folding assays for use in vivo.

Unfortunately, these assays were solely developed for using in bacterial cells and there are currently no effective methods to monitor protein misfolding/aggregation in mammalian cells. Although, the ease of bacterial cell culture is an underlying factor for using these approaches, many cellular processes which are key to the stability of the final conformation of the protein, are absent in bacterial cells. It is of particular importance to make sure that mammalian proteins are expressed in a physiologically relevant system. The focus of this research is to re-examine the EGFP reporter system, typically utilized in bacterial cells for monitoring protein misfolding/aggregation, in mammalian cells Since the cellular environments and processes in mammalian cells are extremely complex, it is vital to understand protein folding/aggregation in more physiologically relevant systems. More importantly, this assay will be a great analytical tool for monitoring protein misfolding/aggregation of biopharmaceuticals. 


\section{Background and Theoretical Development}

\subsection{Monitoring Protein Misfolding/Aggregation Using Fluorescent Reporter Proteins}

\section{$\underline{2.1 .1 G F P}$}

Following the development of life-or-death assay using CAT and the $\beta$-Gal fusion proteins expressed in E.coli, Waldo et al. first employed the use of fluorescent proteins tagged to the $\mathrm{C}$-terminus of a target protein to examine the aggregation and folding status of the target protein in vivo. Green fluorescent protein (GFP) is a powerful and one of the most widely used tools in cellular biology. GFP can be fused with another protein to quantify and visualize the expression of protein. Folding reporter GFP (frGFP) has been designed to report if a protein has folded correctly or not, especially for proteins that are found in the cytoplasm of a cell (Waldo, 2003; Waldo et al, 1999). When the frGFP is tagged to the $\mathrm{C}$-terminus of a target protein, the fluorescence signal cells expressing the fusion protein is directly proportional to how correctly the target protein has folded. GFP fusion proteins have also been used as an assay to screen large libraries of molecules. We have seen in other aggregate-prone disorders like Alzheimer's where folding reporter GFP was used to monitor protein folding. Kim and co-workers created a high-throughput screening method which monitored fluorescence intensity of the amyloid-beta 42-GFP fusion protein when in the presence of compound that could potentially inhibit protein aggregation (Kim et al, 2006). Searching through compounds in such a manner allows for parallel experiments and the ability to screen through a vast library of compounds in a timely fashion. When fused to a protein of choice, the folding 
reporter GFP (frGFP) developed by Waldo et al. correlates the correctness of folding with the fluorescence intensity of the protein, serving a real-time folding reporter of the protein. This frGFP has been characterized in bacterial cells for screening compounds inhibiting aggregation of amyloid-beta peptide associated with Alzheimer's disease. It has also been used to monitor intrabody formation in aggregates within mammalian and bacterial cells.

A mutant form of GFP, venus yellow fluorescent protein (vYFP) has been used as a folding reporter. vYFP has intrinsic properties that make it an attractive candidate as a reporter protein. In comparison to GFP, it forms its fluorophore at a faster rate, has increased folding efficiency and remains stable in harsh cellular environments. Arslan and Chakrabartty first reported the use of vYFP as a reporter protein in a cell-free method to monitor the aggregation of the $A \beta-42$ peptide. They were able to screen a library of peptides that can facilitate the folding of $A \beta-42$ in a cis- manner in E. coli. This new reporter protein shows extreme promise in its ability to monitor protein misfolding in living cells (Arslan \& Chakrabartty, 2009; Arslan et al, 2010).

Cabantous, Terwillinger and Waldo developed a novel folding reporter assay that was similar in concept to the "live or die" assays, utilizing self-complementary GFP (split GFP)(Cabantous et al, 2005a; Cabantous et al, 2005c; Cabantous \& Waldo, 2006). A short, non-fluorescent 15-amino acid portion (GFP 11) of GFP is tagged to the CTerminus of a target protein, reducing the influence of the GFP folding on the misfolding/aggregation of the target protein. To complete the fluorophore, the other portion of GFP (GFP 1-10) must complement with the GFP11 fusion tag. Target proteins that are misfolded/insoluble will reduce the accessibility of this portion of the GFP, 
making self-complementation difficult and reducing the fluorescence of the fusion protein. Highly soluble and well folded proteins will form the full-length GFP, fluorescing brightly. This technique can also be performed in bacteria and mammalian cells, making it a very attractive technique for monitoring protein folding/ aggregation. In his pioneering work, Johnson et al. reported a novel split GFP complementation system to monitor aggregation of mutant tau proteins, which is associated with Alzheimer's disease, in mammalian cells (Chun et al, 2007). However, efficient complementation of the split GFP fragments requires a delicate control of relative (and absolute) expression levels of two split GFP fragments (Chun et al, 2007), restricting diverse applications such as stable cell line generation where relative expression level control of two fragments is not trivial. Furthermore, since the split GFP complementation is based on the assumption that the small GFP fragment fused to a target protein in aggregates have very limited accessibility to a large GFP fragment, this method may not be effective when a target protein forms loosely packed aggregates enabling access of the small GFP fragment to the large fragment. Therefore, the need remains to develop a simple but effective quantitative assay for protein misfolding and aggregation in mammalian cells.

There are issues with examining the aggregation of a heterodimer using the split GFP. If the proteins in a complex are soluble when expressed separately, but insoluble once the complex is formed, the split GFP system could not accurately determine the level of aggregation of the protein complex. In order to address this issue, Lockard et al added an additional 6-histidine tag to the N-Terminus of the target protein while keeping the GFP11 tag on the C-terminus of the target protein (Lockard et al, 2011). Once cells expressing the fusion protein are lysed, the proteins are directly captured on immobilized 
beads. By incorporating an affinity tag to the detection system, they were able to create a novel screening system that would give insight on total protein expression as well as soluble protein levels.

\subsubsection{ZsGreen}

Similar to the GFP fusion protein, Heddle and Mazaley tested the reef coral fluorescent protein (RCFP) as a aggregation reporter (Heddle \& Mazaleyrat, 2007). The tertiary structures of the RCFPs and GFP are similar and emit fluorescence at similar levels as GFP at reduced noises levels, making RCFPs an attractive choice for potential monitoring systems. They determined that ZsGreen, a RCFP, shows most promise as a folding reporter because of its ability to not alter the aggregation of the target protein when it is tagged to the C-Terminus of the target protein. Also, it was able to differentiate between poorly folded and well folded proteins when quantifying the levels of soluble protein as well as average cellular fluorescence.

\subsection{Monitoring Protein Misfolding/Aggregation Using Selective Pressures}

\subsection{1 $\beta$-Lactamase}

Foit et al developed a novel screening system to monitor the folding state of a target protein using a tripartite fusion system (Foit et al, 2009). This fusion protein is designed such that the test protein is flanked by two fragments of the penicillin resistance gene, TEM-1- $\beta$-lactamase. TEM-1 $\beta$-lactamase is a small, monomeric protein that hydrolyzes the $\beta$-lactam ring on most penicillins. When the two fragments are separated, 
similar to split GFP, the antibiotic resistance protein has no activity. However, when the enzyme is intact, it retains its enzymatic activity.

The basis for the fusion method is that if a protein is misfolded or unstable, the two fragments that are fused to the $\mathrm{N}$ - and $\mathrm{C}$ - termini of the target protein will not be able to form the intact TEM1- $\beta$-lactamase enzyme, leading to reduction of enzymatic activity. Using penicillin as the antibiotic to select bacteria that express well folded fusion proteins, the system is able to give insight on in vitro thermodynamic stability. The benefits of the tripartite fusion protein system are that it reduces the number of false positives that occur frequently in other systems, can be applied to proteins regardless of size and the species the protein is typically expressed in and gives a quantitative output on the thermodynamic stability of the protein. Also, the fusion protein is expressed within the periplasm of the cell, whereas other fusion protein systems are typically expressed within the cytoplasm of the cell. The system has been applied to examining protein folding in periplasmic space, antibody-antigen interactions, and single chain antibody aggregation (Mansell et al, 2008; Mansell et al, 2010).

\subsubsection{Expression of Soluble Proteins by Random Incremental Truncation(ESPRIT)}

Many of the monitoring systems of protein misfolding/ aggregation involve indirect C-terminus fusions using a fluorescent protein or antibiotic resistance proteins. However, the these systems increase the probability of "false positives" due to proteolytic cleavage of the target protein or increased aggregation of the target protein caused by the soluble nature of the reporter protein. To address these issues, Yumeredendi et al. developed a novel aggregation assay where the target genes are cloned into a vector 
containing a short linear biotin acceptor peptide as well as a hexahistidine tag at the Nterminus of the target protein (Yumerefendi et al, 2010). Soluble proteins are more likely to have their peptide accessible for biotin binding, making detection of biotinylation possible using streptavidin. However, aggregated or misfolded proteins will reduce the ability for the peptide to become biotinylated and detected using streptavidin. Using antihexahistidine antibodies, they were able to distinguish intact and soluble proteins from truncated or poorly soluble proteins. This system was first used to determine soluble domains of PB2, the influenza polymerase. The system was also expanded to examining the aggregation of protein complexes, called the Co-ESPRIT system (An et al, 2011).

To improve upon this system, the fragmented library is cloned between an inteinbased open reading frame selection plasmid. The incorporation of the intein-based plasmid will remove many out of frame genes that were present in the initial form of the system. This led to a 9-fold enhancement in screening power, and led to only in frame genes being screened after the first selective pressure was applied to the system (An et al, 2011).

\subsubsection{Murine Dihydrofolate Reductase (mDHFR)}

mDHFR is an enzyme that is essential for reducing dihydrofolic acid to tetrahydrofolic acid. It is imperative for $E$. coli survival. It is also known that trimethoprim (TMP) is known to inhibit the activity of DHFR in different species, but has no effect on mDHFR. As a folding reporter, mDHFR is tagged to the N-Terminus of the target protein. Similar to the frGFP, the folding of GFP is highly dependent upon the folding of the target protein. When the fusion protein is overexpressed in E. coli, only 
cells that express correctly folded mDHFR will survive when in the presence of TMP. Dyson et al were able to utilize this system to find protein constructs that are capable of soluble expression in E. coli (Dyson, 2010; Dyson et al, 2008). It was also used in accordance with the split GFP system to screen a library of fragmented genes of two proteins to determine domains of proteins that are recalcitrant. The minimal effect on the target protein aggregation is an attractive characteristic for monitoring protein aggregation as well as its ability to be expressed in high quantities in E. coli.

\subsection{Choice of Model Protein}

Wild-type SOD1 $\left(\right.$ SOD1 $\left.{ }^{\mathrm{WT}}\right)$ and three aggregation-prone SOD1 mutants $\left(\mathrm{SOD} 1^{\mathrm{A} 4 \mathrm{~V}}, \mathrm{SOD} 1^{\mathrm{A} 4 \mathrm{~V} / \mathrm{C} 57 \mathrm{~S},}\right.$ and $\left.\mathrm{SOD} 1^{\mathrm{A} 4 \mathrm{~V} / \mathrm{C} 111 \mathrm{~S}}\right)$ were chosen as model proteins. SOD ${ }^{\mathrm{A} 4 \mathrm{~V}}$ is known to form aggregates in vitro and in vivo (Auclair et al, 2010; Banci et al, 2008; Hough et al, 2004; Schmidlin et al, 2009; Shaw et al, 2006). Among four cysteines (Cys6, Cys57, Cys111, and Cys146), two free cysteines Cys6 and Cys111 are known to form inter-molecular disulfide bond network with other SOD1 monomers containing free C6 or C111 during the aggregation process (Cozzolino et al, 2008; de Beus et al, 2004; Fujiwara et al, 2007; Niwa et al, 2007a). Therefore, Cys to Ser mutation at residue 111 of SOD1 reduces SOD1 aggregation (de Beus et al, 2004; Niwa et al, 2007a). $\mathrm{SOD} 1^{\mathrm{A} 4 \mathrm{~V} / \mathrm{C} 111 \mathrm{~S}}$ mutant is more stable and soluble than SOD1 ${ }^{\mathrm{A} 4 \mathrm{~V}}$ mutant in cultured cells and in vitro (Cozzolino et al, 2008; Fujiwara et al, 2007; Watanabe et al, 2007), indicating that $\mathrm{SOD} 1^{\mathrm{A} 4 \mathrm{~V} / \mathrm{C} 111 \mathrm{~S}}$ has a lower misfolding/aggregation propensity than $\mathrm{SOD}^{\mathrm{A} 4 \mathrm{~V}}$. The other two cysteines, C57 and C147, are involved in an intra-subunit 
disulfide bond formation; an important post-translational modification of SOD1. It was reported that removing a Cys residue involved in the intra-subunit disulfide bond formation greatly destabilizes the protein and so enhances misfolding of the protein in cultured cells and in vitro (Cozzolino et al, 2008; Furukawa et al, 2006; Niwa et al, 2007b; Watanabe et al, 2007), indicating that the misfolding propensity of SOD1 ${ }^{\mathrm{A} 4 \mathrm{~V} / \mathrm{C} 57 \mathrm{~S}}$ is higher than that of SOD1 ${ }^{\mathrm{A} 4 \mathrm{~V}}$. In summary, for the four SOD1 mutants used in this study, the order of extent of deviations from correctly folded structure (misfolding/aggregation) is $\mathrm{SOD}^{\mathrm{A} 4 \mathrm{~V} / \mathrm{C} 57 \mathrm{~S}}>\mathrm{SOD}^{\mathrm{A} 4 \mathrm{~V}}>\mathrm{SOD}^{\mathrm{A} 4 \mathrm{~V} / \mathrm{C} 111 \mathrm{~S}}>$ and $^{\mathrm{SOD}} 1^{\mathrm{WT}}$. 


\section{$\underline{3 \text { Research Scope and Objectives }}$}

\subsection{Research Scope}

The scope of the first chapter of this thesis is to develop a monitoring system that allows for non-invasive quantification of protein misfolding/aggregation in mammalian cells. In order to validate the GFP fusion method's capacity to monitor protein misfolding/aggregation in mammalian cells, human copper/zinc superoxide dismutase (SOD1) mutants, which are associated with neurodegenerative disorder familial form of amyotrophic lateral sclerosis (Prudencio et al, 2009; Ray et al, 2005; Rosen et al, 1993; Shaw \& Valentine, 2007; Wang et al, 2008; Zhang \& Zhu, 2006a), were chosen as model proteins due to their favorable features. First, SOD1 mutants form intracellular aggregates in mammalian cells in a relatively short period time, usually within two to three days post-transfection (Atkin et al, 2006; Niwa et al, 2007a; Sau et al, 2007). Second, there are over one hundred natural SOD1 mutants with varying misfolding/aggregation propensities, though wild-type SOD1 forms a stable dimer (Banci et al, 2008; Galaleldeen et al, 2009; Rakhit \& Chakrabartty; Valentine et al, 2005; Zhang \& Zhu, 2006b). Third, SOD1 mutants are known to form loosely packed aggregates inside mammalian cells (Matsumoto et al, 2006) and so the split GFP complementation may not be effective in monitoring protein aggregation. Herein we investigated whether there is a direct correlation between misfolding/aggregation propensity of the four SOD1 variants and mean cellular fluorescence of transfected HEK293T cells expressing the corresponding SOD1 variant fused to GFP. 


\subsection{Research Objectives}

The purpose of this study is to test our novel protein misfolding/aggregation monitoring system in mammalian cells, a human embryonic kidney cell line. The system consists of fusing EGFP to the C-terminus of our target protein and overexpressing the fusion protein in the various mammalian cell lines. The following objectives were completed in order to confirm the monitoring assay is comparable to the assay currently used for monitoring protein misfolding/aggregation in mammalian cells, the split-GFP assay, and determine that the changes in fluorescence are solely linked to protein misfolding/aggregation.

1. Compare split GFP complementary system to EGFP fusion protein system

a. Obtain average cellular fluorescence of HEK293T cells expressing SOD $1^{\mathrm{WT}}$ and SOD $1^{\mathrm{A} 4 \mathrm{~V}}$ fused to EGFP and split GFP

b. Obtain fluorescence microscopy images of cells expressing EGFP fusion protein to determine qualitative aggregation patterns

2. Determine whether fluorescence changes in EGFP system are directly linked to SOD1 misfolding/aggregation

a. Qualitatively compare fluorescence of HEK293T cells using fluorescence microscopy

b. Obtain protein expression levels of fusion protein by cell lysis and immunostaining to determine if variation in protein expression levels play a substantial role in cellular fluorescence 
c. Obtain transfection efficiencies to determine whether variation in cellular fluorescence is linked to transfection efficiencies

d. Use of various promoters to see whether promoter strength has an effect on fluorescence

e. Repeat experiments in a motor neuron-like cell line (NSC-34) to evaluate the generality of the system 


\section{Materials and Methods}

\subsection{Materials.}

HRP-conjugated anti-GFP and anti-rabbit antibodies were obtained from Invitrogen (Carlsbad, CA). Anti- $\alpha$ tubulin antibody was obtained from Sigma-Aldrich (St. Louis, MO). HEK293T and NSC-34 cells were obtained from Invitrogen and CELLutions Biosystems (Burlington, Ontario, Canada), respectively. Restriction enzymes and DNA ligases were obtained from New England Biolabs (Ipswich, MA). All other chemicals were obtained from Sigma-Aldrich, unless otherwise noted.

\subsection{Methods}

\subsubsection{Construction of Expression Vectors.}

The EGFP gene is located at the $3^{\prime}$ end of either SOD $1^{\mathrm{WT}}$ or SOD $1^{\mathrm{A} 4 \mathrm{~V}}$ gene in

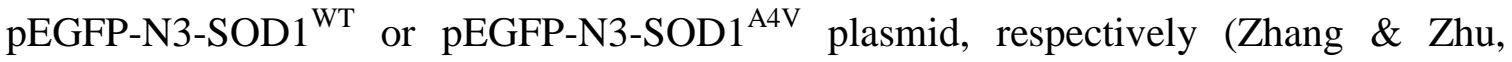
2006a). In both plasmids, SOD1-EGFP fusion protein expression is under the control of Cytomegalovirus (CMV) constitutive promoter. Cysteine (Cys) to serine (Ser) mutation was introduced into either Cys57 or Cys111 residue of $\mathrm{SOD} 1^{\mathrm{A} 4 \mathrm{~V}}$ by PCR mutagenesis using pEGFP-N3-SOD $1^{\mathrm{A} 4 \mathrm{~V}}$ as a template in order to generate $\mathrm{pEGFP-N3-SOD} 1^{\mathrm{A} 4 \mathrm{~V} / \mathrm{C} 57 \mathrm{~S}}$ or pEGFP-N3-SOD1 ${ }^{\mathrm{A} 4 \mathrm{~V} / \mathrm{C} 111 \mathrm{~S}}$ plasmid, respectively. The primer pairs for each mutant were as follows: 5'- GGAGATAATACAGCAGGCAGCACCAGTGCAGGTCCTCAC 3' and 5' GTGAGGACCTGCACTGGTGCTGCCTGCTGTATTATCTCC-3' for the C57S mutation and 5'CTCACTCTCAGGAGACCATAGCATCATTGGCCGCACACTG-3’; 
CAGTGTGCG GCCAATGATGCTATGGTCTCCTGAGAGTGAG for the C111S mutation. In the pFUG-IP plasmid, expression of GFP protein is under the control of ubiquitin-C constitutive promoter (Ubc) (Jang et al, 2011). In order to express SOD1EGFP fusion protein using Ubc promoter, the SOD1-EGFP genes were amplified from the pEGFP-N3-SOD1 plasmids using two pairs of primers flanked by AgeI and EcoRI sites at both ends (forward primer for SOD $1^{\mathrm{WT}}$ : 5'GATCACACCGGTATGGCGACGAAGGCCGTGTGCGTGCTGA-3’; forward primer for SOD1 $^{\mathrm{A} 4 \mathrm{~V}}:$ 5'-GATCACACCGGTATGGCGACGAAGGTCGTGTG-3'; reverse primer for both SOD1s: 5'-GTCATCGAATTCTTACTTGTACAGCTCGTCCA). Then, the SOD1-EGFP genes were sub-cloned into the pFUG-IP plasmid 3' of the Ubc promoter. In order to sub-clone the CMV-SOD1-EGFP cassette into pFUG-IP plasmid backbone, a unique PacI restriction site in the pFUG-IP plasmid was mutated into an EocRI restriction site via PCR mutagenesis using the following primers (forward: 5'CGCATGGACGAGCTGTACAAGTAAGGCGCGCCCCCTCTCCCTCCCCCC-3’;

reverse:

5'GGGGGGAGGGAGAGGGGGCGCGCCTTACTTGTACAGCTCGTCCATGCCG-3’). The CMV-SOD1-EGFP cassette was amplified from the pEGFP-N3-SOD1 plasmid using two primers flanked with $A s c \mathrm{I}$ and $\mathrm{PacI}$ restriction sites at both ends (forward: 5'GCATTAATAACCTGATTCTGTGGATAACCG-3'; reverse: 5'CAGGGCGCGCCTTTATTTGTAACCATTATAA-3') and were sub-cloned into the pFUGIP. 


\subsubsection{Transfection of HEK293T and NSC-34 cells.}

HEK293T cells were cultured on 6-well plates at $37^{\circ} \mathrm{C}$ in Dulbecco's modified Eagle's medium/High Glucose (DMEM/High Glucose, Thermo Scientific, Pittsburg, PA) supplemented with $10 \%$ fetal bovine serum (FBS), $100 \mu \mathrm{g} / \mathrm{mL}$ of streptomycin sulfate and 100 units/ml of penicillin. NSC-34 cells were maintained in DMEM/12:1:1 modified containing $10 \%$ FBS. When the cells grew to $80-90 \%$ confluency, they were transfected with appropriate plasmids via calcium phosphate precipitation (Graham \& van der Eb, 1973; Jang et al, 2011). All samples were tested in triplicate, unless otherwise described explicitly.

\subsubsection{Fluorescence Microscopy.}

At two days after transfection, the transfected HEK293T cells cultured on the 6well plates were visualized by fluorescence microscopy using a VistaVision Inverted Fluorescence Microscope (VWR, Radnor, PA). Fluorescence microscopic images of the cells were taken with a DV-2C digital camera equipped on the microscope at the same magnification and camera settings. The fluorescence excitation wavelength is between 420 and 485 and the emission wavelength is $515 \mathrm{~nm}$. The number of cells in the fluorescence microscopy images was manually counted. The percentage of transfected cells exhibiting SOD1-EGFP aggregates was determined by dividing the number of aggregate-containing cells by the number of total cells analyzed.

\subsubsection{Flow Cytometric Analysis of Cellular Fluorescence.}

After incubating the desired amount of time, the fluorescence intensities of the HEK293T and NSC-34 cells expressing SOD1 variant-EGFP fusion protein were 
measured using the C6 flow cytometer (Accuri, Ann Arbor, MI). To prepare the cells for flow cytometric analysis, the HEK 293T cells and NSC-34 cells were trypsinized, washed twice with phosphate buffered saline buffer (PBS; $\mathrm{pH}$ 7.4) and diluted ten-fold in PBS to prevent cell aggregation. The excitation wavelength was $488 \mathrm{~nm}$ and the fluorescence emission was detected at $585 \mathrm{~nm}$. Only GFP positive cells were used to calculate the mean cellular fluorescence. Transfection efficiency was determined by dividing the number of fluorescence positive cells by the number of total cells analyzed. Each sample was prepared in triplicate and cellular fluorescence indicates mean cellular fluorescence, unless otherwise noted. Student's paired t-test was used for statistical analysis of fluorescence data.

\subsubsection{Dot-blotting.}

$1 \times 10^{5}$ transfected HEK293T cells were centrifuged to obtain a cell pellet. The cell pellet was washed with PBS buffer once and was lysed using RIPA buffer (Thermo Fisher, Pittsburgh, PA). Protein concentration of the cell lysate was determined using BCA kit (Pierce, Rockford, IL) using bovine serum albumin as a standard. Dot-blot assay of the cell lysate was performed as described earlier (Wong \& Kwon, 2011; Wong et al, 2011) except antibodies used (anti- $\alpha$ tubulin and HRP-conjugated anti-GFP antibodies in this study). The blot images were captured using a BioSpectrum imaging system (UVP). 


\section{Results and Discussion}

\subsection{Fluorescence Microscopic Observation of Transfected HEK293T Cells Expressing SOD1 Variants.}

HEK293T cells were transfected with plasmids encoding each of the four SOD1EGFP variants genes (SOD1 ${ }^{\mathrm{WT}}$-EGFP, SOD1 ${ }^{\mathrm{A} 4 \mathrm{~V} / \mathrm{C} 111 \mathrm{~S}}-\mathrm{EGFP}, \mathrm{SOD} 1^{\mathrm{A} 4 \mathrm{~V}}-\mathrm{EGFP}$, and SOD1 $1^{\mathrm{A} 4 \mathrm{~V} / \mathrm{C} 57 \mathrm{~S}}$-EGFP). At two days post-transfection, fluorescence images of the transfected cells were taken using a fluorescence microscope (Figure 5.1). Transfected HEK293T cells expressing SOD1 ${ }^{\text {WT }}$-EGFP were brightest among the four different transfected cells. The order of brightness of the transfected cells expressing four SOD1 variants fused to EGFP is $\mathrm{SOD} 1^{\mathrm{WT}}>\mathrm{SOD} 1^{\mathrm{A} 4 \mathrm{~V} / \mathrm{C} 111 \mathrm{~S}}>\mathrm{SOD} 1^{\mathrm{A} 4 \mathrm{~V}}>$ and $^{\mathrm{SOD}} 1^{\mathrm{A} 4 \mathrm{~V} / \mathrm{C} 57 \mathrm{~S}}$, which is consistent with the inverse order of misfolding/aggregation propensity of the four SOD1 variants in vitro and in cultured cells previously reported (Cozzolino et al, 2008; Fujiwara et al, 2007; Watanabe et al, 2007).

\subsection{Flow Cytometric Analysis of Transfected HEK293T Cells Expressing SOD1 Variants.}

Fluorescence microscopic observation of cells expressing GFP fusion protein is a non-invasive method to qualitatively compare the fluorescence intensities of different cell samples but is not suitable for quantitative analysis. Therefore, we employed flow cytometric analysis of the transfected HEK293T cells to evaluate cellular fluorescence. At one and two days post-transfection of HEK293T cells with plasmids encoding four SOD1-EGFP fusion genes respectively, the mean fluorescence intensities of the four transfected cells were measured by flow cytometry (Figure 5.2(A)). In this article, the 

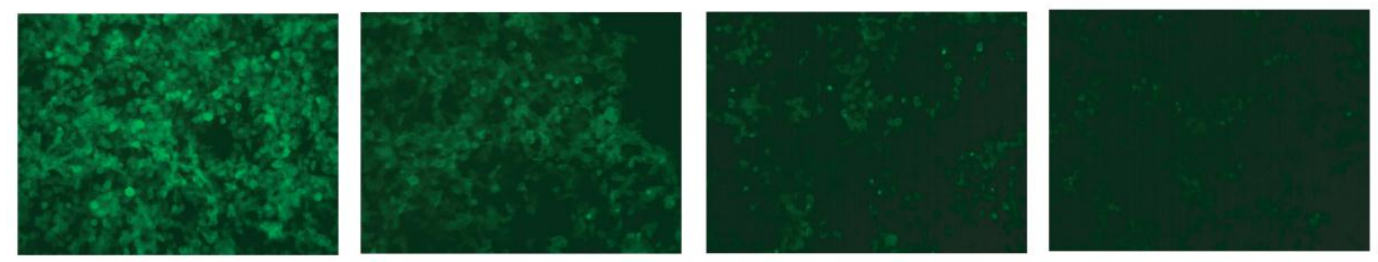

\begin{tabular}{|c|c|c|c|c|}
\hline SOD1 variant & SOD $1^{\text {WT }}$ & $S O D 1^{A 4 V / C 111 S}$ & $\operatorname{SOD}^{A \mathrm{AV}}$ & $S O D 1^{A Q V C 575}$ \\
\hline Transfection efficiency (\%) & $55 \pm 5$ & $55 \pm 4$ & $50 \pm 3$ & $42 \pm 2$ \\
\hline
\end{tabular}

Figure 5.1: Fluorescence microscopy images of the transfected HEK293T cells expressing SOD1 variants fused to EGFP. Images of transfected HEK293T cells expressing EGFP fusion of SOD $1^{\mathrm{WT}}, \mathrm{SOD} 1^{\mathrm{A} 4 \mathrm{VC} 111 \mathrm{~S}}, \mathrm{SOD} 1^{\mathrm{A} 4 \mathrm{~V}}$, and $\mathrm{SOD} 1^{\mathrm{A} 4 \mathrm{~V} / \mathrm{C} 57 \mathrm{~S}}$ taken at two days post-transfection. Transfection efficiency for each SOD1 variant was determined by calculating the percentage of GFP positive cells out of total cells analyzed using flow cytometry. Values represent means \pm standard deviation $(n=3)$. 

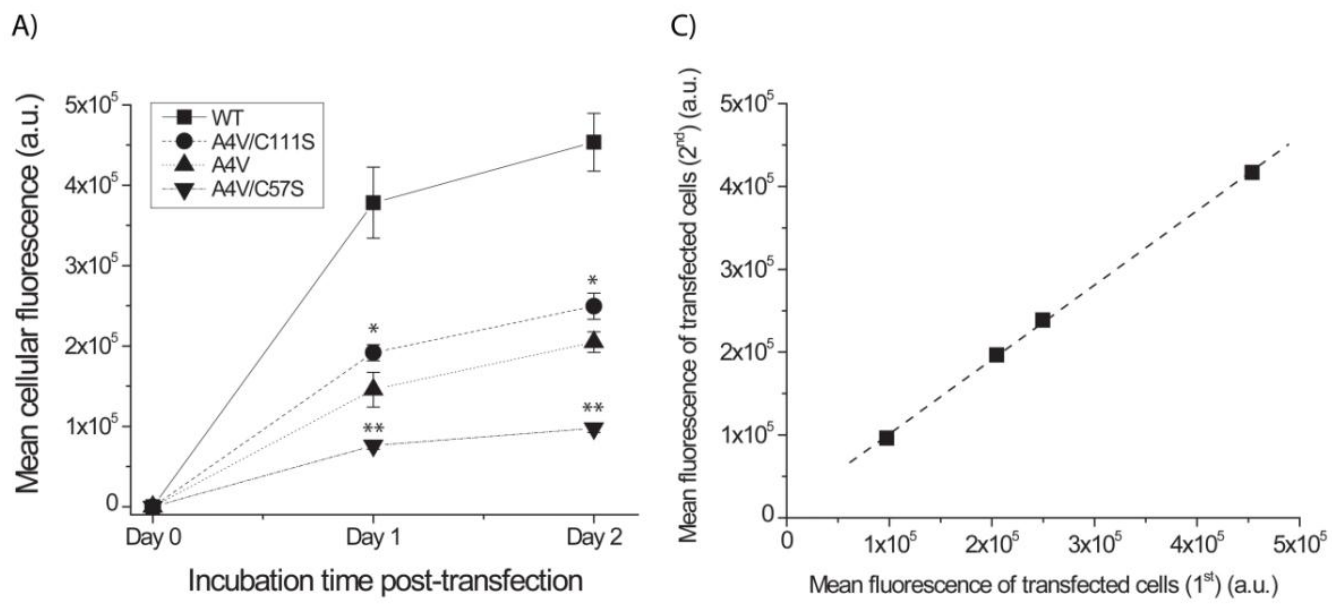

B)

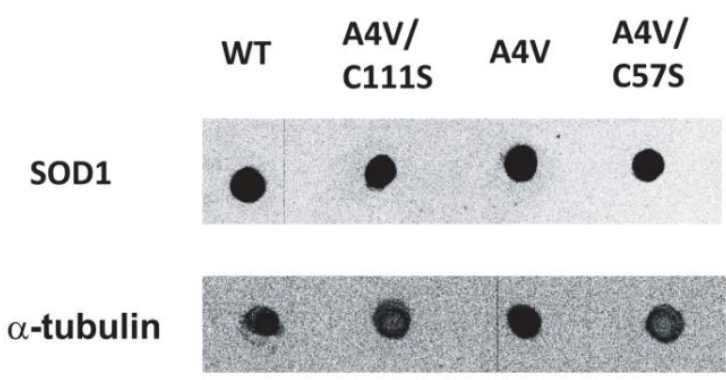

Figure 5.2: Comparison of the cellular fluorescence intensities and expression levels of EGFP fusion of SOD1 variants. (A) Time course of fluorescence intensities of the transfected HEK293T cells expressing EGFP fusion of SOD1 variants. Fluorescence intensities of untransfected cells (day 0) and transfected cells expressing EGFP fusion of four SOD1 variants (SOD1 ${ }^{\mathrm{WT}}, \mathrm{SOD} 1^{\mathrm{A} 4 \mathrm{VC} 111 \mathrm{~S}}, \mathrm{SOD} 1^{\mathrm{A} 4 \mathrm{~V}}$, and $\left.\mathrm{SOD} 1^{\mathrm{A} 4 \mathrm{~V} / \mathrm{C} 57 \mathrm{~S}}\right)$ at day 1 and 2 were determined by flow cytometry. Fluorescence intensities of cells expressing $\mathrm{SOD} 1^{\mathrm{A} 4 \mathrm{~V} / \mathrm{C} 111 \mathrm{~S}}$ or SOD1 ${ }^{\mathrm{A} 4 \mathrm{~V} / \mathrm{C} 57 \mathrm{~S}}$ were significantly higher $(* ; \mathrm{P}<0.05)$ or lower $(* * ; \mathrm{P}<$ 0.001) than those of cells expressing $\mathrm{SOD}^{\mathrm{A} 4 \mathrm{~V}}$, respectively, at days 1 and 2 posttransfection. Values and error bars represent mean cellular fluorescence and standard deviations, respectively $(\mathrm{n}=3)$. Two-sided Student's t-tests were applied to the data. (B) Dot-blot images from the cell lysates of EGFP fusion of SOD $1^{\mathrm{WT}}$ and SOD1 ${ }^{\mathrm{A} 4 \mathrm{~V}} \cdot \alpha-$ tubulin levels of SOD $1^{\mathrm{WT}}$ and $\mathrm{SOD}^{\mathrm{A} 4 \mathrm{~V}}$ determined using anti- $\alpha$ tubulin monoclonal 
antibody were compared to ensure loading of similar amount of protein samples. Expression levels of EGFP fusion of SOD1 ${ }^{\mathrm{WT}}$ and SOD $1^{\mathrm{A} 4 \mathrm{~V}}$ were compared using antiGFP polyclonal antibody. (C) Comparison of the mean cellular fluorescence of HEK293T cells expressing SOD1 variants that were transfected at two separate days. At two days post-transfection, cellular fluorescence of transfected HEK293T cells expressing EGFP fusion of SOD1 variants $\left(\mathrm{SOD} 1^{\mathrm{WT}}, \mathrm{SOD} 1^{\mathrm{A} 4 \mathrm{VC} 111 \mathrm{~S}}, \mathrm{SOD} 1^{\mathrm{A} 4 \mathrm{~V}}\right.$, and $\mathrm{SOD}^{\mathrm{A} 4 \mathrm{~V} / \mathrm{C} 57 \mathrm{~S}}$ ) was determined by flow cytometry. The data were fitted to a straight line $\left(\mathrm{R}^{2}=0.99\right) . \quad($ a.u. $=$ arbitrary unit $)$ 
fluorescence intensities measured by flow cytometry indicate the mean cellular fluorescence intensities. As expected, the order of fluorescence intensity of the four transfected cells is $\mathrm{SOD} 1^{\mathrm{WT}}>\mathrm{SOD} 1^{\mathrm{A} 4 \mathrm{~V} / \mathrm{C} 111 \mathrm{~S}}>\mathrm{SOD}^{\mathrm{A} 4 \mathrm{~V}}>\mathrm{SOD} 1^{\mathrm{A} 4 \mathrm{~V} / \mathrm{C} 57 \mathrm{~S}}$, matching the inverse order of the misfolding/aggregation propensities of the four SOD1 variants. The cellular fluorescence intensity of SOD $1^{\mathrm{A} 4 \mathrm{~V} / \mathrm{C} 111 \mathrm{~S}}$ was significantly higher than that of $\mathrm{SOD}^{\mathrm{A} 4 \mathrm{~V}}(\mathrm{P}<0.05)$, whereas the cellular fluorescence intensity of SOD1 ${ }^{\mathrm{A} 4 \mathrm{~V} / \mathrm{C} 57 \mathrm{~S}}$ was significantly lower than that of $\mathrm{SOD}^{\mathrm{A} 4 \mathrm{~V}}(\mathrm{P}<0.001)$ (Figure 5.2(A)).

Although flow cytometric analysis of cellular fluorescence is a very convenient way to obtain information on cellular processes, caution should be taken to directly correlate the cellular fluorescence intensities to protein misfolding/aggregation. Other factors such as transfection efficiency and expression level of a target protein can also affect the fluorescence intensity of transfected cells. First, effects of transfection efficiencies on cellular fluorescence were investigated. The transfection efficiencies of the four SOD1 variants were determined by flow cytometry. The transfection efficiency was calculated by the number of GFP positive cells by the number of total cells analyzed by flow cytometry. Although the transfection efficiencies vary from $42 \%$ to $55 \%$, the differences are not big enough to explain the differences in cellular fluorescence of the four different transfected cells, supporting the idea that cellular fluorescence intensity is related to SOD1 properties. The transfection efficiencies of SOD1 ${ }^{\mathrm{A} 4 \mathrm{~V}}$ and SOD1 ${ }^{\mathrm{A} 4 \mathrm{~V} / \mathrm{C} 57 \mathrm{~S}}$ were 5 to $13 \%$ lower than those of SOD $1^{\mathrm{WT}}$ and SOD $1^{\mathrm{A} 4 \mathrm{~V} / \mathrm{C} 111 \mathrm{~S}}$, which is most likely due to the exclusion of some weak fluorescent cells in the samples. If the fluorescence intensity of the transfected cells are overlapped with that of untransfected cells (negative control), such weak fluorescent cells are not counted to determine the mean cellular 
fluorescence intensity after the background subtraction in flow cytometric analysis. According to the transfection efficiencies measured by flow cytometry (Figure 5.1), the maximum difference among the transfection efficiencies was $13 \%$. However, this difference is too small to explain the more than 4-fold difference in the fluorescence intensities of cells expressing SOD $1^{\mathrm{WT}}$ and SOD $1^{\mathrm{A} 4 \mathrm{~V} / \mathrm{C} 57 \mathrm{~S}}$ (Figure 5.2(A)). Furthermore, the lower transfection efficiency of SOD $1^{\mathrm{A} 4 \mathrm{~V} / \mathrm{C} 57 \mathrm{~S}}$ cell sample is most likely made by the exclusion of weakly fluorescent cells from the transfection efficiency calculation due to the background subtraction in data analysis. If the weak fluorescent cells were included to correct the transfection efficiency, the cellular fluorescence intensities would decrease, making the difference in the cellular fluorescence intensities between SOD1 ${ }^{\text {WT }}$ and SOD1 ${ }^{\mathrm{A} 4 \mathrm{~V} / \mathrm{C} 57 \mathrm{~S}}$ bigger. Therefore, our results suggest that the low transfection efficiencies of SOD1 ${ }^{\mathrm{A} 4 \mathrm{~V}}$ and SOD1 $1^{\mathrm{A} 4 \mathrm{~V} / \mathrm{C} 57 \mathrm{~S}}$ are not the major cause of their low cellular fluorescence.

Second, we investigated whether the differences in the cellular fluorescence intensities resulted from differences in the expression levels of SOD1 variants, because the mean fluorescence intensities of cells expressing correctly folded GFP can change according to GFP expression level. As a representative case, expression levels of SOD $1^{\mathrm{WT}}$-EGFP and SOD $1^{\mathrm{A} 4 \mathrm{~V}}$-EGFP were compared using dot-blot assay. Since HEK293T cells also express endogenous SOD1 ${ }^{\text {WT }}$, we employed anti-GFP antibody to compare expression levels of both fusion proteins. Transfected cells expressing either SOD $1^{\mathrm{WT}}$-EGFP or SOD1 ${ }^{\mathrm{A} 4 \mathrm{~V}}$-EGFP were lysed and the total cell lysates were used for dot-blot assay. Anti- $\alpha$ tubulin antibody was used to ensure spotting comparable amount of the protein extracts to a nitrocellulose membrane (Figure 5.2(B bottom)). The immuno-reactivity of SOD $1^{\mathrm{A} 4 \mathrm{~V}}$-EGFP was slightly weaker than that of SOD $1^{\mathrm{WT}}$-EGFP, 
which might be explained by $5 \%$ difference in the transfection efficiencies. However, the immune-reactivity difference was too small to explain the 2-fold difference in the mean cellular fluorescence intensities between SOD $1^{\mathrm{WT}}$-EGFP and $\mathrm{SOD} 1^{\mathrm{A} 4 \mathrm{~V}}$-EGFP (Figure 5.2(B top)). Therefore, the expression level of EGFP fusion of SOD1 variants was not the cause of substantial changes in the cellular fluorescence intensities.

Third, besides transfection efficiency and expression level, there might be other factors that affect cellular fluorescence intensities. If there are other critical factors affecting the cellular fluorescence intensities, the results may not be reproducible. In order to confirm the reproducibility of the results, transfection and cellular fluorescence measurement were performed on two separate days with a month gap. Then, the mean fluorescence intensities of the transfected cells obtained from two independent experiments were compared (Figure 5.2(C)). For the four SOD1-EGFP variants

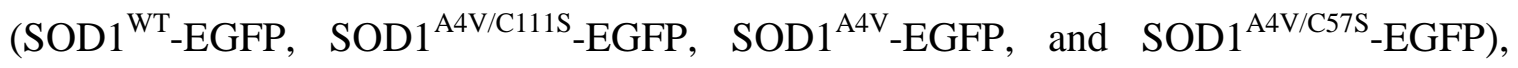
there is a linear correlation between the cellular fluorescence intensities of the cells transfected on two separate days $\left(\mathrm{R}^{2}=0.99\right)$, though there was a slight difference in the absolute fluorescence intensities (around 5\%). Our results strongly indicate that the correlation between the cellular fluorescence intensities and the misfolding/aggregation propensities of the SOD1 variants is quite reproducible. However, since absolute fluorescence intensities of the transfected cells expressing EGFP fusion protein may vary each time, an accurate estimation of misfolding/aggregation status of a target protein requires a calibration using both highly stable and misfolding/aggregation-prone protein controls. 


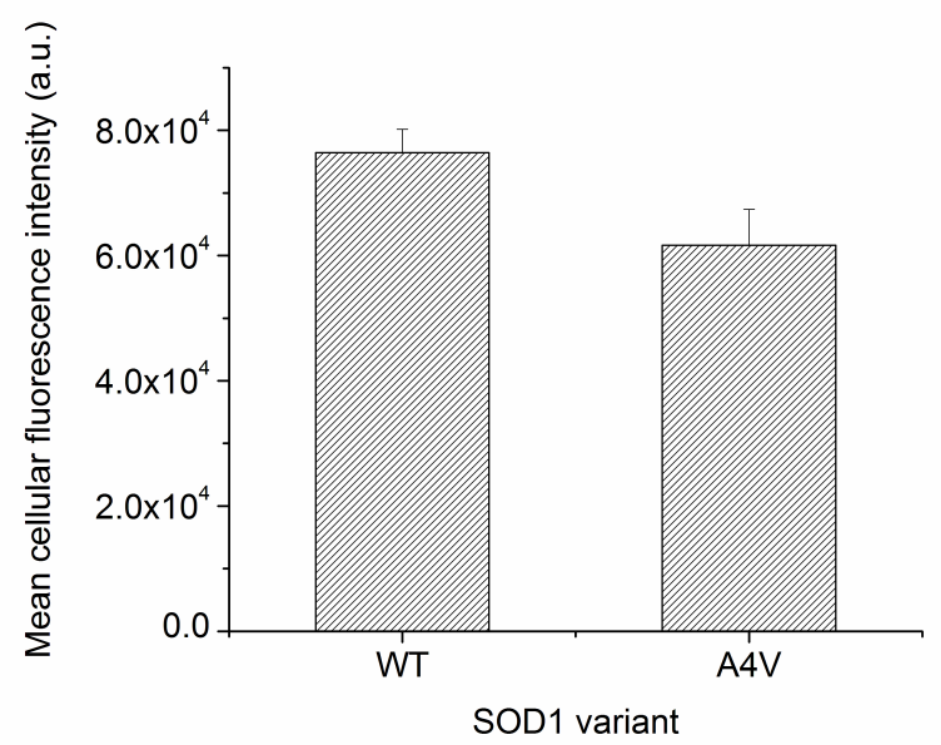

Figure 5.3. Mean cellular fluorescence intensities of transfected HEK293T cells co-expressing split GFP fragments fused to SOD1 ${ }^{\mathrm{WT}}$ or $\mathrm{SOD1}^{\mathrm{A4V}}$. In order to achieve split GFP complementation, both pCMV-mGFP_1-10 and pCMVmGFP_Cterm_S11 plasmids encoding large and small GFP fragment gene respectively, which are originally developed by Waldo group, were obtained from Theranostech, Inc. (Albuquerque, NM) (Cabantous et al, 2005b; Cabantous \& Waldo, 2006). PCRamplified $\mathrm{SOD}^{\mathrm{WT}}$ and $\mathrm{SOD}^{\mathrm{A} 4 \mathrm{~V}}$ genes were inserted between NheI and BamHI restriction sites of pCMV-mGFP_Cterm_S11 to generate pCMV_SOD1 ${ }^{\text {WT }}$-mGFP_S11 and pCMV-SOD1 ${ }^{\mathrm{A} 4 \mathrm{~V}}$-mGFP_S11, respectively. HEK293T cells were co-transfected with pCMV-mGFP_1-10 and either pCMV_SOD1 ${ }^{\mathrm{WT}}-\mathrm{mGFP} \_\mathrm{S} 11$ or ${ }^{\mathrm{pCMV}-S O D} 1^{\mathrm{A} 4 \mathrm{~V}}$ mGFP_S11 plasmid. Mean cellular fluorescence intensities of the transfected HEK293T cells were determined by flow cytometry at two days post-transfection. Values indicate the mean cellular fluorescence intensities and standard deviations $(n=3)$. 
In order to compare the efficacy of EGFP fusion to that of split GFP complementation, split GFP complementation was performed on SOD1 ${ }^{\mathrm{WT}}$ and SOD1 ${ }^{\mathrm{A} 4 \mathrm{~V}}$. The mean cellular fluorescence intensities of SOD $1^{\mathrm{WT}}$ and $\mathrm{SOD} 1^{\mathrm{A} 4 \mathrm{~V}}$ were not significantly different (Figure 5.3), which is likely due to loosely packed structure of SOD $1^{\mathrm{A} 4 \mathrm{~V}}$ aggregates (Matsumoto et al, 2006) allowing access of a small fragment of GFP fused to SOD $1^{\mathrm{A} 4 \mathrm{~V}}$ to a large GFP fragment. This finding suggests the idea that EGFP fusion is more effective in monitoring protein aggregation, which is loosely packed, than split GFP complementation.

\subsection{Aggregate Formation of SOD1 ${ }^{\mathrm{A} 4 \mathrm{~V}}$ Variants in Transfected HEK293T Cells.}

Our results indicate that transfected cells expressing EGFP fusion of SOD1 variants exhibited significant disparity in the mean cellular fluorescence intensity but the disparity was not caused by differences in the transfection efficiency or expression level of the SOD1 variants. Therefore, it is reasonable to assume that there are substantial differences in the structures of the SOD1 variants. We hypothesized that the disparity in fluorescence intensities of cells expressing the SOD1 variants result from differences in the extent of misfolding, aggregation, or both of the SOD1 variants. Transfected cells expressing four SOD1-EGFP variants were re-examined using fluorescence microscopy

with a higher magnification (400X). Transfected cells expressing SOD ${ }^{\mathrm{A} 4 \mathrm{~V}}$ exhibited visible aggregates inside cells whereas cellular fluorescence of the transfected cells expressing SOD $1^{\mathrm{WT}}$ is evenly distributed in the cytosol (Figure 5.4(A)), consistent with the 
results previously reported (Witan et al, 2008). Similar intracellular aggregates were found in both transfected cells expressing SOD1 $1^{\mathrm{A} 4 \mathrm{~V} / \mathrm{C} 111 \mathrm{~S}}$ and SOD1 ${ }^{\mathrm{A} 4 \mathrm{~V} / \mathrm{C} 57 \mathrm{~S}}$, respectively

(Figure 5.4(A)). The percentage of cells containing intracellular aggregates was determined by examining the fluorescence microscopic images of the transfected cells. Over five hundred cells for each SOD1 variant were analyzed and the results were plotted (Figure $5.4(\mathrm{~B}))$. Around $12 \%$ of the transfected cells expressing SOD1 ${ }^{\mathrm{A} 4 \mathrm{~V}}$ exhibited intracellular aggregates, whereas none of the transfected cells expressing SOD1 ${ }^{\text {WT }}$ showed any intracellular aggregates. However, approximately 5\% of the cells expressing SOD1 $1^{\mathrm{A} 4 \mathrm{~V} / \mathrm{C} 111 \mathrm{~S}}$ showed aggregates, consistent with the reduced aggregation of $\mathrm{SOD}^{\mathrm{A} 4 \mathrm{~V} / \mathrm{C} 111 \mathrm{~S}}$ compared to $\mathrm{SOD} 1^{\mathrm{A} 4 \mathrm{~V}}$ in mammalian cells (Cozzolino et al, 2008). Therefore, the significant increase $(\mathrm{P}<0.05)$ in the cellular fluorescence intensity of cells expressing SOD1 ${ }^{\mathrm{A} 4 \mathrm{~V} / \mathrm{C} 111 \mathrm{~S}}$ over that of $\mathrm{SOD}^{\mathrm{A} 4 \mathrm{~V}}$ (Figure $5.2(\mathrm{~A})$ ) is attributed to the reduced aggregation of SOD $1^{\mathrm{A} 4 \mathrm{~V} / \mathrm{C} 111 \mathrm{~S}}$ compared to SOD1 ${ }^{\mathrm{A} 4 \mathrm{~V}}$ (Figure 5.4(B)). In the case of SOD1 $1^{\mathrm{A} 4 \mathrm{~V} / \mathrm{C} 57 \mathrm{~S}}, 10 \%$ of the transfected cells exhibited intracellular aggregates but the difference from $\mathrm{SOD}^{\mathrm{A} 4 \mathrm{~V}}$ is not statistically significant $(\mathrm{P}>0.05)$. Rather, the percentage of cells exhibiting SOD1-EGFP aggregates determined by fluorescence microcopy does not correlate well to an increase in the cellular fluorescence intensity. However, the enhanced misfolding propensity of SOD $1^{\mathrm{A} 4 \mathrm{~V} / \mathrm{C} 57 \mathrm{~S}}$ over $\mathrm{SOD} 1^{\mathrm{A} 4 \mathrm{~V}}$ (Cozzolino et al, 2008), which severely inhibits correct folding of GFP, is better attributed to a loss of fluorescence. In Figure 5.2(A), the change in the cellular fluorescence caused by C57S mutation was greater than the change caused by $\mathrm{C} 111 \mathrm{~S}$, which can be explained by the greater extent of structural perturbations made by aggregation and misfolding. Considering that the loss of an intra-subunit disulfide bond 
caused by C57S mutation generates very unstable monomeric SOD1s, structural perturbation of SOD1 caused by C57S mutation is likely greater than that of SOD1 caused by intermolecular disulfide network-mediated aggregation. 
A)

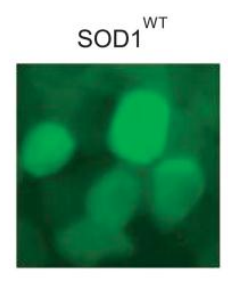

A4V/C1115

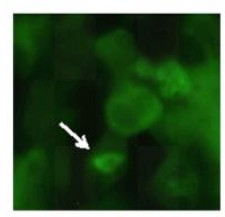

A4V/C575

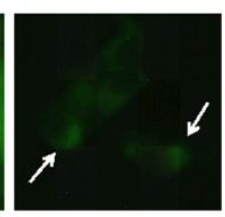

B)

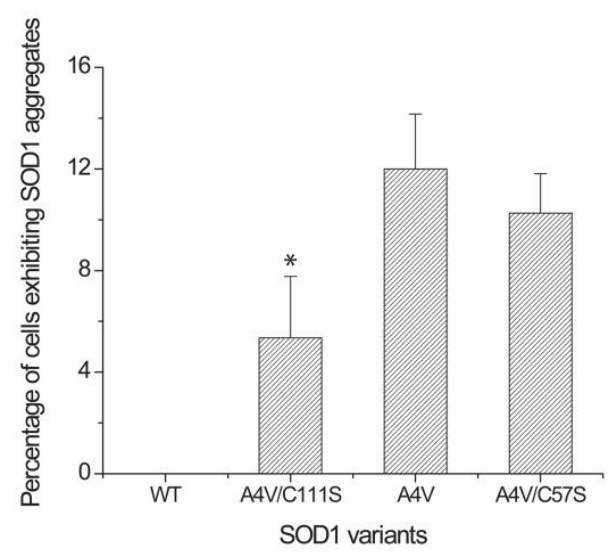

Figure 5.4: Aggregate formation of $\mathrm{SOD}^{\mathrm{A4V}}$ in transfected HEK293T cells. (A) Fluorescence microscopic images of the transfected HEK293T cells expressing EGFP fusion of SOD1 variants. Images of transfected HEK293T cells expressing EGFP fusion of SOD $1^{\text {WT }}$ and SOD $1^{\mathrm{A} 4 \mathrm{~V}}$ were taken at two days post-transfection. SOD $1^{\text {WT }}$-EGFP is almost evenly distributed in the cytosol but SOD $1^{\mathrm{A} 4 \mathrm{~V}}$-EGFP forms aggregates. Arrows indicate the aggregates within the cell. (B) The percentage of transfected HEK293T cells exhibiting SOD1 aggregates. The number of cells exhibiting intracellular SOD1 aggregates was determined by analyzing fluorescence microscopy images of the transfected cells expressing EGFP fusion of four SOD1 variants (SOD1 ${ }^{\mathrm{WT}}$, $\mathrm{SOD} 1^{\mathrm{A} 4 \mathrm{VC} 111 \mathrm{~S}}, \mathrm{SOD} 1^{\mathrm{A} 4 \mathrm{~V}}$, and $\mathrm{SOD} 1^{\mathrm{A} 4 \mathrm{~V} / \mathrm{C} 57 \mathrm{~S}}$ ) at day two post-transfection. The percentage of aggregates-found cells expressing SOD1 $1^{\mathrm{A} 4 \mathrm{~V} / \mathrm{C} 111 \mathrm{~S}}$ was significantly lower $(* ; \mathrm{P}<0.05)$ compared to that of $\mathrm{SOD} 1^{\mathrm{A} 4 \mathrm{~V}}$. Values and error bars represent mean and standard deviations, respectively $(n=3)$. Two-sided Student's t-tests were applied to the data. 
In summary, mean cellular fluorescence intensity of cells expressing EGFP fusion of SOD1 variant is a good indicator of deviations (combined effects of misfolding and aggregation) from correctly folded structure. However, caution should be taken when correlating the cellular fluorescence intensity to only either aggregation or misfolding of SOD1 variants, because both aggregation and misfolding of SOD1 variant may not occur simultaneously.

\subsection{Comparison of the Cellular Fluorescence of Transfected NSC-34 and HEK293T Cells Expressing SOD1 Variants.}

In the transfected HEK293T cells expressing four SOD1-EGFP variants, there was good quantitative correlation between the cellular fluorescence intensity and the combined misfolding and aggregation propensities. In order to confirm that the correlation is valid in cells other than HEK293T cells, mouse neuroblastoma NSC-34 cells (Cashman et al, 1992) were also examined at two days post-transfection using flow cytometric analysis similar to the transfected HEK293T cells. NSC-34 cell is a widely used cell line to study SOD1 expression in cultured cells (Babetto et al, 2005; Kupershmidt et al, 2009; Raimondi et al, 2006; Rizzardini et al, 2006; Tartari et al, 2009). Even in the transfected NSC-34 cells, the order of cellular fluorescence intensities match well with the inverse order of misfolding/aggregation propensities of the SOD1 variants (Figure 5.5(A)). In order to determine whether there is a direct correlation between the mean fluorescence intensities of HEK293T and NSC-34 cells expressing the four SOD1EGFP variants, the mean cellular fluorescence intensities of both cells were plotted (Figure 5.5(B)). The fluorescence ratios of SOD1 variant over SOD1 ${ }^{\mathrm{WT}}$ in NSC-34 cells 
were similar to those in HEK293T cells. Furthermore, a linear correlation between the fluorescence intensities of both transfected cells was observed $\left(\mathrm{R}^{2}=0.98\right)$, indicating that an inverse relationship between the cellular fluorescence intensity and the misfolding/aggregation propensity of SOD1 variants is valid in both cell lines. However, the fluorescence intensities of the transfected NSC-34 cells are about one half of that of the corresponding transfected HEK293T cells, which can be explained by weaker biosynthesis activities in slow growing NSC-34 cells. Therefore, in order to estimate extent of the deviation of a target protein from its correctly folded structure in a specific cell line, cellular fluorescence intensities should be calibrated using appropriate positive and negative control samples. 
A)

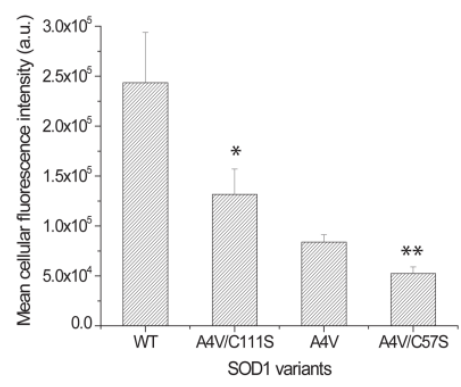

B)

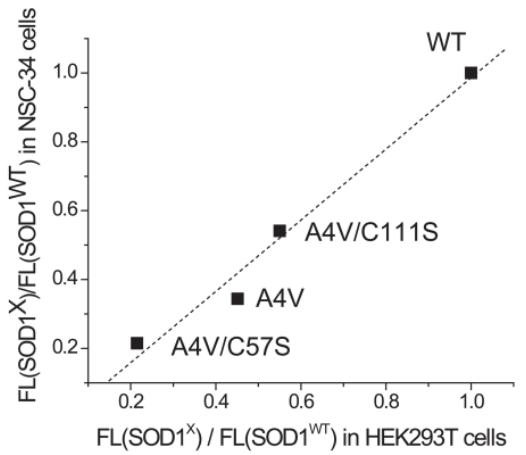

Figure 5.5. Comparison of the orders of fluorescence intensities of transfected HEK293T and NSC-34 cells expressing EGFP fusion of SOD1 variants. (A) Fluorescence intensities of the transfected NSC-34 cells expressing EGFP fusion of SOD1 variants $\left(\mathrm{SOD} 1^{\mathrm{WT}}, \mathrm{SOD} 1^{\mathrm{A} 4 \mathrm{VC} 111 \mathrm{~S}}, \mathrm{SOD} 1^{\mathrm{A} 4 \mathrm{~V}}\right.$, and $\left.\mathrm{SOD} 1^{\mathrm{A} 4 \mathrm{~V} / \mathrm{C} 57 \mathrm{~S}}\right)$ at two days posttransfection were determined by flow cytometry. Fluorescence intensities of cells expressing $\mathrm{SOD} 1^{\mathrm{A} 4 \mathrm{~V} / \mathrm{C} 111 \mathrm{~S}}$ or $\mathrm{SOD} 1^{\mathrm{A} 4 \mathrm{~V} / \mathrm{C} 57 \mathrm{~S}}$ were significantly higher $(* ; \mathrm{P}<0.05)$ or lower (**; $\mathrm{P}<0.01)$ than those of cells expressing $\mathrm{SOD} 1^{\mathrm{A} 4 \mathrm{~V}}$. Values and error bars represent mean cellular fluorescence and standard deviations, respectively $(n=3)$. Twosided Student's t-tests were applied to the data. (a.u. = arbitrary unit) (B) Comparison of the cellular fluorescence of the transfected HEK293T at day two and NSC-34 cells at day three post-transfection. The cellular fluorescence of transfected HEK293T and NSC-34 cells expressing EGFP fusion of SOD1 variants (SOD1 ${ }^{\mathrm{WT}}, \mathrm{SOD} 1^{\mathrm{A} 4 \mathrm{VC} 111 \mathrm{~S}}, \mathrm{SOD} 1^{\mathrm{A} 4 \mathrm{~V}}$, and SOD $1^{\mathrm{A} 4 \mathrm{~V} / \mathrm{C} 57 \mathrm{~S}}$ ) was determined by flow cytometry. The data were fitted to a straight line $\left(\mathrm{R}^{2}=0.98\right)$. $\mathrm{FL}\left(\mathrm{SOD} 1^{\mathrm{X}}\right) / \mathrm{FL}\left(\mathrm{SOD} 1^{\mathrm{WT}}\right)$ indicates the ratio of fluorescence intensity of cells expressing a SOD1 variant $\left(\mathrm{SOD}^{\mathrm{X}}\right)$ over the fluorescence intensity of cells expressing SOD $1^{\mathrm{WT}}$. 


\subsection{Comparison of the CMV and Ubiquitin-C Promoters.}

Thus far SOD1-EGFP fusion proteins were expressed under control of CMV constitutive promoter. We chose CMV promoter because it is widely used to express recombinant proteins in mammalian cells due to its relatively strong promoter activity in diverse cell lines (Qin et al, 2010). However, we can imagine situations where a different promoter should be used. Therefore, we examined whether the choice of promoter affects the correlation between the cellular fluorescence intensity and SOD1 variant misfolding/aggregation. In order to compare promoters, we chose Ubc promoter which is also widely used in mammalian cells (Qin et al, 2010). SOD $1^{\mathrm{WT}}$-EGFP and SOD1 ${ }^{\mathrm{A} 4 \mathrm{~V}}$ EGFP genes were sub-cloned into pFUG-IP lentiviral vector plasmid (Jang et al, 2011) where a target gene is under the control of ubiquitin-C (Ubc) promoter and an internal ribosome entry site/puromycin resistance gene cassette is located at 3' of a target gene. HEK293T cells were transfected with the plasmids encoding either SOD ${ }^{\text {WT }}$-EGFP or $\mathrm{SOD}^{\mathrm{A} 4 \mathrm{~V}}$-EGFP gene under the control of Ubc promoter. At two days post-transfection, fluorescence intensities of the transfected cells were determined by flow cytometry. The cellular fluorescence intensity of cells expressing $\mathrm{SOD} 1^{\mathrm{A} 4 \mathrm{~V}}$-EGFP was about six-fold lower than that of cells expressing SOD $1^{\text {WT }}$-EGFP (Figure 5.6), indicating that Ubc promoter also allows distinction of cellular fluorescence intensities depending on their misfolding/aggregation propensity of SOD1 variants. The six-fold difference between the cellular fluorescence intensities of SOD $1^{\mathrm{WT}}$-EGFP and $\mathrm{SOD} 1^{\mathrm{A} 4 \mathrm{~V}}$-EGFP with Ubc promoter is greater than the two-fold difference with CMV promoter. Such a greater difference might be caused by the change of promoter from CMV to Ubc and/or the change of plasmid backbone from pEGFP-N3 to pFUG-IP. In order to investigate this, 
we replaced the Ubc promoter in the pFUG-IP plasmid backbone with CMV promoter. The cellular fluorescence intensity of cells transfected with the modified pFUG-IP plasmid carrying CMV-SOD ${ }^{\text {WT }}$-EGFP cassette was around four-fold greater than that of CMV-SOD $1^{\mathrm{A} 4 \mathrm{~V}}$-EGFP cassette in the same plasmid backbone, which suggests that the pFUG-IP plasmid backbone plays an important role in increasing the difference between the cellular fluorescence intensities of SOD $1^{\mathrm{WT}}$-EGFP and $\mathrm{SOD} 1^{\mathrm{A} 4 \mathrm{~V}}-\mathrm{EGFP}$. It is noteworthy that the pFUG-IP plasmid encodes a puromycin resistant gene as well as a target protein gene. Therefore, it is possible that chaperone proteins facilitating folding of unstable $\mathrm{SOD} 1^{\mathrm{A} 4 \mathrm{~V}}$ are less available to $\mathrm{SOD} 1^{\mathrm{A} 4 \mathrm{~V}}$, because the chaperone proteins are also involved in the folding of co-expressed puromycin resistant protein, which reduce the correct folding of SOD1 ${ }^{\mathrm{A} 4 \mathrm{~V}}$. In order to investigate this hypothesis, we co-transfected HEK293T cells with both pEGFP-N3-SOD1 ${ }^{\text {A4V }}$ and pAAV-Luc (a plasmid encoding luciferase gene under the control of CMV promoter) plasmids and also observed six-fold difference between the fluorescence intensities of SOD $1^{\mathrm{WT}}$-EGFP and SOD $1^{\mathrm{A} 4 \mathrm{~V}}$-EGFP with co-expression of luciferase protein (Figure 5.7). The fluorescence intensity of cells expressing SOD $1^{\mathrm{WT}}$-EGFP under the control of Ubc promoter was about 5-fold lower than that of CMV promoter (Figure 5.6), likely due to weaker activity of Ubc promoter than CMV promoter in HEK293T cells (Qin et al, 2010). As expected, when the Ubc promoter in the pFUG-IP backbone was replaced with CMV promoter, the cellular fluorescence intensities of cells expressing both SOD $1^{\mathrm{WT}}$-EGFP and SOD $1^{\mathrm{A} 4 \mathrm{~V}}$-EGFP increased two fold (Figure 5.6). In summary, both CMV and Ubc promoters enable distinction of cellular fluorescence depending on misfolding/aggregation propensity of SOD1 variants. 


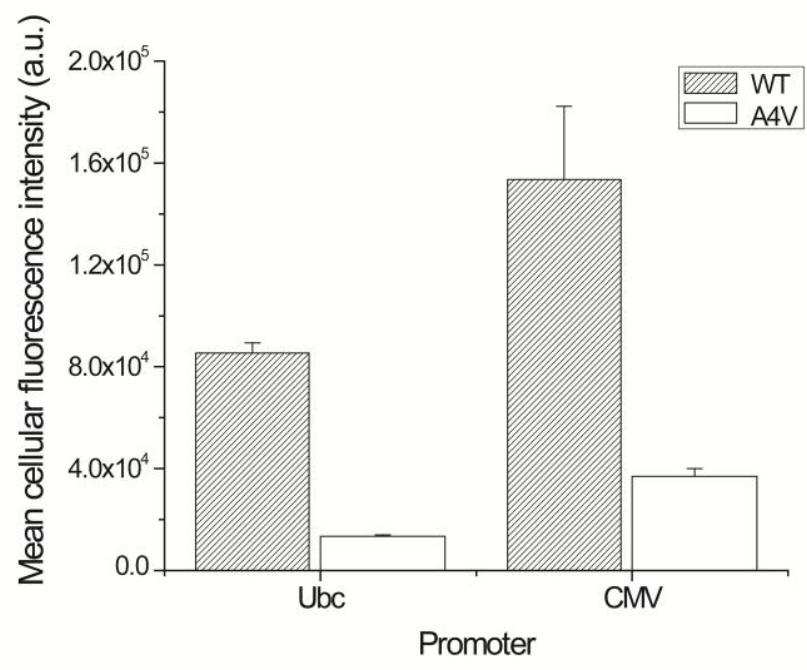

Figure 5.6. Comparison of CMV and Ubc promoter activities for the fluorescence intensities of transfected HEK293T cells expressing EGFP fusion of SOD1 variants. Cellular fluorescence of HEK293Tcells expressing EGFP fusion of SOD1 ${ }^{\text {WT }}$ and $\mathrm{SOD}^{\mathrm{A} 4 \mathrm{~V}}$ under the control of either $\mathrm{CMV}$ or Ubc promoter was determined by flow cytometry. Values and error bars represent mean cellular fluorescence and standard deviations, respectively $(\mathrm{n}=3)$. (a.u. = arbitrary unit) 


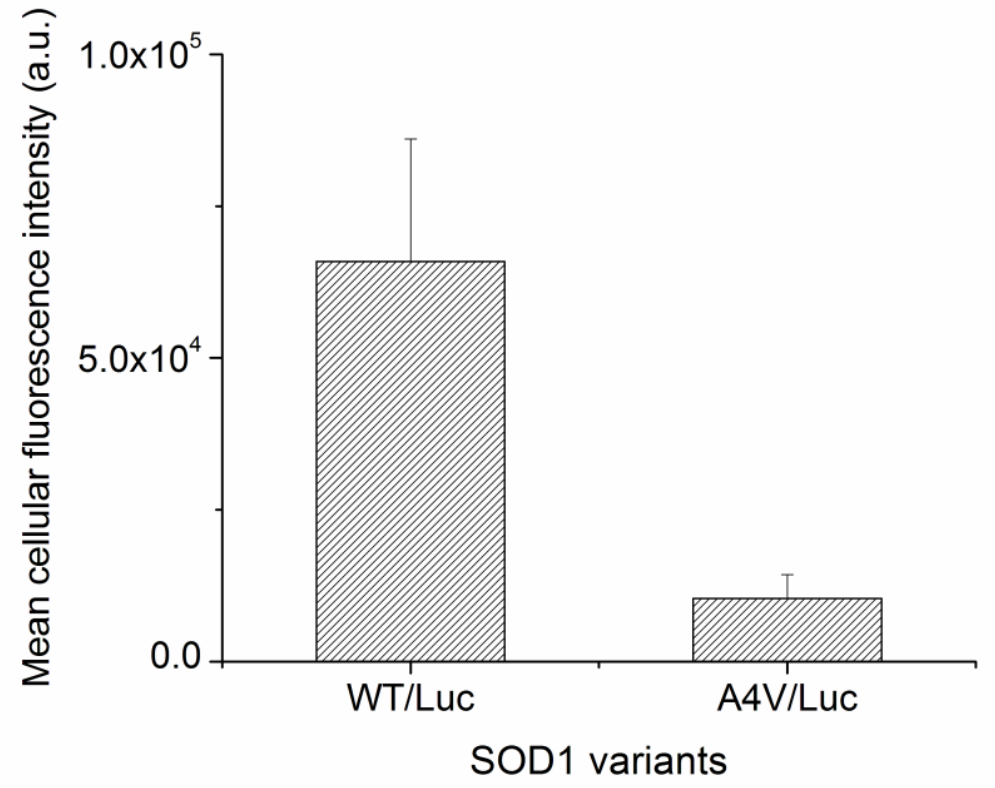

Figure 5.7. Mean cellular fluorescence intensities of transfected HEK293T cells coexpressing firefly luciferase (Luc) and either SOD1 ${ }^{\mathrm{WT}}$-EGFP or SOD1 $^{\mathrm{A} 4 \mathrm{~V}}$-EGFP. pAAV-Luc plasmid encodes Luc gene under the control of CMV promoter (Jang et al, 2010). HEK293T cells were co-transfected with pAAV-Luc and either pEGFP-N3SOD1 ${ }^{\mathrm{WT}}$ or $\mathrm{pEGFP-N3-SOD} 1^{\mathrm{A} 4 \mathrm{~V}}$ plasmid. Mean cellular fluorescence intensities of the transfected HEK293T cells were determined by flow cytometry at two days posttransfection. Values indicate the mean cellular fluorescence intensities and standard deviations $(n=3)$. 


\section{Conclusions}

Our investigation has conclusively established that EGFP fused to the C-terminus of SOD1 variants allows determination of the extent of deviations from the correctly folded structure of SOD1 via the cellular fluorescence measurement. The order of fluorescence intensities of the transfected cells expressing four SOD1 variants correlates well to the inverse order of misfolding/aggregation propensities of the four SOD1 variants in both HEK293 and NSC-34 cells. Therefore, the mean cellular fluorescence of cells expressing EGFP fusion of a target protein is a good indicator of misfolding/aggregation of the target protein.

All research objectives were met:

1. Compare split GFP complementary system to EGFP fusion protein system

2. Prior to this investigation, the split GFP assay was the only system available for monitoring protein misfolding/aggregation in mammalian cells. However, my results showed that the split GFP system is not sensitive enough to distinguish the extents of misfolding/aggregation between $\mathrm{SOD}^{\mathrm{WT}}$ and $\mathrm{SOD} 1^{\mathrm{A} 4 \mathrm{~V}}$ variant. However, the EGFP fusion method that I have developed provides a significant difference in their cellular fluorescence intensities, which distinguish the extents of misfolding/aggregation between SOD $1^{\mathrm{WT}}$ and $\mathrm{SOD} 1^{\mathrm{A} 4 \mathrm{~V}}$ variant.

3. Determine whether fluorescence changes in EGFP system are directly linked to SOD1 misfolding/aggregation 
To validate that the results of the quantitative assay (flow cytometric analysis) were attributed solely to the variations in the misfolding/aggregation of the SOD1 variants, other factors that potentially affect cellular fluorescence (protein expression level, reproducibility, and transfection efficiency) were evaluated. In all cases, there were no significant changes in the cellular fluorescence of the SOD1 variants due to these potential factors. Although the absolute fluorescence intensities were higher in one cell line in comparison to another, trends observed in the HEK293T cell line were also observed in a mouse neuroblastoma cell line (NSC-34). Also, when a weaker promoter, such as Ubc, was used to express the fusion protein, similar trends were observed in the average cellular fluorescence.

Although forthcoming studies are required to generalize these findings to other proteins and cell lines, our studies would open a new door to monitor misfolding/aggregation of numerous target proteins in mammalian cell systems. 


\section{Recommendations}

Flow cytometric monitoring of mutant SOD1 aggregation in cultured cells is a simple, but effective method that provides an array of structural information on mutant SOD1. More broadly, generality of GFP tagging method will easily allow extension of this method to monitoring other cytosolic proteins that readily form aggregates. As an application of this monitoring system and more particularly to understanding the mechanism of SOD1 aggregation, we will seek to use this protein folding/aggregation monitoring method as a screening method for proteins that have the capability of stabilizing SOD1 ${ }^{\mathrm{A} 4 \mathrm{~V}}$.

Amyotrophic lateral sclerosis (ALS) is the most common motor neuron disease in humans, leading to muscle spasticity paralysis and death within five years of diagnosis (Cleveland \& Rothstein, 2001). Currently, there are no effective treatments for preventing or curing ALS and so there remains great need to develop effective therapeutics. Researchers believe there is a synergistic link between misfolding/aggregation of the human copper/zinc superoxide dismutase proteins (SOD1) mutants and their role in the toxic function in familial form of ALS (fALS) (Bruijn et al, 1998; Rosen et al, 1993). With the rapid advancements in ALS research, this assay would serve as a powerful tool in understanding the pathological mechanism and developing treatments for fALS. 


\section{Literature Cited}

An Y, Yumerefendi H, Mas PJ, Chesneau A, Hart DJ (2011) ORF-selector ESPRIT: a second generation library screen for soluble protein expression employing precise open reading frame selection. J Struct Biol 175: 189-197. Epub 2011 Apr 2016.

Arslan PE, Chakrabartty A (2009) Probing Alzheimer amyloid peptide aggregation using a cell-free fluorescent protein refolding method. Biochem Cell Biol 87: 631-639.

Arslan PE, Mulligan VK, Ho S, Chakrabartty A (2010) Conversion of Abeta42 into a folded soluble native-like protein using a semi-random library of amphipathic helices. $J$ Mol Biol 396: 1284-1294. Epub 2009 Dec 1221.

Atkin JD, Farg MA, Turner BJ, Tomas D, Lysaght JA, Nunan J, Rembach A, Nagley P, Beart PM, Cheema SS, Horne MK (2006) Induction of the Unfolded Protein Response in Familial Amyotrophic Lateral Sclerosis and Association of Protein-disulfide Isomerase with Superoxide Dismutase 1. J Biol Chem 281: 30152-30165

Auclair JR, Boggio KJ, Petsko GA, Ringe D, Agar JN (2010) Strategies for stabilizing superoxide dismutase (SOD1), the protein destabilized in the most common form of familial amyotrophic lateral sclerosis. Proc Natl Acad Sci U S A

Babetto E, Mangolini A, Rizzardini M, Lupi M, Conforti L, Rusmini P, Poletti A, Cantoni L (2005) Tetracycline-regulated gene expression in the NSC-34-tTA cell line for investigation of motor neuron diseases. Mol Brain Res 140: 63-72

Banci L, Bertini I, Boca M, Girotto S, Martinelli M, Valentine JS, Vieru M (2008) SOD1 and amyotrophic lateral sclerosis: mutations and oligomerization. PLoS One 3: e1677

Bruijn LI, Houseweart MK, Kato S, Anderson KL, Anderson SD, Ohama E, Reaume AG, Scott RW, Cleveland DW (1998) Aggregation and motor neuron toxicity of an ALSlinked SOD1 mutant independent from wild-type SOD1. Science 281: 1851-1854

Cabantous S, Pédelacq JD, Mark BL, Naranjo C, Terwilliger TC, Waldo GS (2005a) Recent advances in GFP folding reporter and split-GFP solubility reporter technologies. Application to improving the folding and solubility of recalcitrant proteins from Mycobacterium tuberculosis. J Struct Funct Genomics 6: 113-119 
Cabantous S, Terwilliger TC, Waldo GS (2005b) Protein tagging and detection with engineered self-assembling fragments of green fluorescent protein. Nat Biotechnol 23: 102-107

Cabantous S, Terwilliger TC, Waldo GS (2005c) Protein tagging and detection with engineered self-assembling fragments of green fluorescent protein. Nat Biotechnol 23: 102-107

Cabantous S, Waldo GS (2006) In vivo and in vitro protein solubility assays using split GFP. Nat Methods 3: 845-854

Cashman NR, Durham HD, Blusztajan JK, Oda K, Tabira T, Shaw IT, Dahrouge S, Antel JP (1992) Neuroblastoma x spinal cord (NSC) hybrid cell lines resemble developing motor neurons. Dev Dyn 194: 209-221

Chun WJ, Waldo GS, Johnson GVW (2007) Split GFP complementation assay: a novel approach to quantitatively measure aggregation of tau in situ: effects of GSK3 beta activation and caspase 3 cleavage. $J$ Neurochem 103: 2529-2539

Cleveland DW, Rothstein JD (2001) From Charcot to Lou Gehrig: deciphering selective motor neuron death in ALS. Nat Rev Neurosci 2: 806-819

Cozzolino M, Amori I, Pesaresi MG, Ferri A, Nencini M, Carri MT (2008) Cysteine 111 affects aggregation and cytotoxicity of mutant $\mathrm{Cu}, \mathrm{Zn}$-superoxide dismutase associated with familial amyotrophic lateral sclerosis. J Biol Chem 283: 866-874

de Beus MD, Chung J, Colón W (2004) Modification of cysteine 111 in $\mathrm{Cu} / \mathrm{Zn}$ superoxide dismutase results in altered spectroscopic and biophysical properties. Protein Sci 13: $1347-1355$

Dyson MR (2010) Selection of soluble protein expression constructs: the experimental determination of protein domain boundaries. Biochemical Society Transactions 38: 908913

Dyson MR, Perera RL, Shadbolt SP, Biderman L, Bromek K, Murzina NV, McCafferty J (2008) Identification of soluble protein fragments by gene fragmentation and genetic selection. Nucleic Acids Res 36: e51. Epub 2008 Apr 2017. 
Foit L, Morgan GJ, Kern MJ, Steimer LR, von Hacht AA, Titchmarsh J, Warriner SL, Radford SE, Bardwell JC (2009) Optimizing protein stability in vivo. Mol Cell 36: 861871.

Fujiwara N, Nakano M, Kato S, Yoshihara D, Ookawara T, Eguchi H, Taniguchi N, Suzuki K (2007) Oxidative Modification to Cysteine Sulfonic Acid of Cys111 in Human Copper-Zinc Superoxide Dismutase. J Biol Chem 282: 35933-35944

Furukawa Y, Fu R, Deng HX, Siddique T, O'Halloran TV (2006) Disulfide cross-linked protein represents a significant fraction of ALS-associated $\mathrm{Cu}, \mathrm{Zn}$-superoxide dismutase aggregates in spinal cords of model mice. Proc Natl Acad Sci U S A 103: 7148-7153

Galaleldeen A, Strange RW, Whitson LJ, Antonyuk SV, Narayana N, Taylor AB, Schuermann JP, Holloway SP, Hasnain SS, Hart PJ (2009) Structural and biophysical properties of metal-free pathogenic SOD1 mutants A4V and G93A. Arch Biochem Biophys 492: 40-47

Graham FL, van der Eb AJ (1973) A new technique for the assay of infectivity of human adenovirus 5 DNA. Virology 52: 456-467

Heddle C, Mazaleyrat SL (2007) Development of a screening platform for directed evolution using the reef coral fluorescent protein ZsGreen as a solubility reporter. Protein Eng Des Sel 20: 327-337. Epub 2007 Jun 2020.

Hough MA, Grossmann JG, Antonyuk SV, Strange RW, Doucette PA, Rodriguez JA, Whitson LJ, Hart PJ, Hayward LJ, Valentine JS, Hasnain SS (2004) Dimer destabilization in superoxide dismutase may result in disease-causing properties: structures of motor neuron disease mutants. Proc Natl Acad Sci U S A 101: 5976-5981

Hwang S-J, Yoon S, Koh G, Lee G (2011) Effects of culture temperature and pH on flagtagged COMP angiopoietin-1 (FCA1) production from recombinant CHO cells: FCA1 aggregation. Appl Microbiol Biotechnol 91: 305-315

Ioannou YA, Bishop DF, Desnick RJ (1992) Overexpression of human alphagalactosidase-A results in its intracellular aggregation, crystallization in lysosomes, and selective secretion. J Cell Biol 119: 1137-1150

Ishii S, Kase R, Okumiya T, Sakuraba H, Suzuki Y (1996) Aggregation of the Inactive Form of Human $\alpha$-Galactosidase in the Endoplasmic Reticulum. Biochem Biophys Res Commun 220: 812-815 
Jang J-H, Koerber JT, Kim J-S, Asuri P, Vazin T, Bartel M, Keung A, Kwon I, Park KI, Schaffer DV (2011) An Evolved Adeno-associated Viral Variant Enhances Gene Delivery and Gene Targeting in Neural Stem Cells. Mol Ther

Jang JH, Koerber JT, Gujraty K, Bethi SR, Kane RS, Schaffer DV (2010) Surface immobilization of hexa-histidine-tagged adeno-associated viral vectors for localized gene delivery. Gene Ther 17: 1384-1389

Kim W, Kim Y, Min J, Kim DJ, Chang YT, Hecht MH (2006) A high-throughput screen for compounds that inhibit aggregation of the Alzheimer's peptide. ACS Chem Biol 1: 461-469

Kupershmidt L, Weinreb O, Amit T, Mandel S, Carri MT, Youdim MBH (2009) Neuroprotective and neuritogenic activities of novel multimodal iron-chelating drugs in motor-neuron-like NSC-34 cells and transgenic mouse model of amyotrophic lateral sclerosis. FASEB J 23: 3766-3779

Lockard MA, Listwan P, Pedelacq JD, Cabantous S, Nguyen HB, Terwilliger TC, Waldo GS (2011) A high-throughput immobilized bead screen for stable proteins and multiprotein complexes. Protein Engineering Design \& Selection 24: 565-578

Mansell TJ, Fisher AC, DeLisa MP (2008) Engineering the protein folding landscape in gram-negative bacteria. Current Protein \& Peptide Science 9: 138-149

Mansell TJ, Linderman SW, Fisher AC, DeLisa MP (2010) A rapid protein folding assay for the bacterial periplasm. Protein Science 19: 1079-1090

Matsumoto G, Kim S, Morimoto RI (2006) Huntingtin and Mutant SOD1 Form Aggregate Structures with Distinct Molecular Properties in Human Cells. J Biol Chem 281: $4477-4485$

Maxwell KL, Mittermaier AK, Forman-Kay JD, Davidson AR (1999) A simple in vivo assay for increased protein solubility. Protein Sci 8: 1908-1911.

Niwa J, Yamada S, Ishigaki S, Sone J, Takahashi M, Katsuno M, Tanaka F, Doyu M, Sobue G (2007a) Disulfide bond mediates aggregation, toxicity, and ubiquitylation of familial amyotrophic lateral sclerosis-linked mutant SOD1. J Biol Chem 282: 2808728095 
Niwa J, Yamada S, Ishigaki S, Sone J, Takahashi M, Katsuno M, Tanaka F, Doyu M, Sobue G (2007b) Disulfide bond mediates aggregation, toxicity, and ubiquitylation of familial amyotrophic lateral sclerosis-linked mutant SOD1. J Biol Chem 282: 2808728095

Okumiya T, Kroos MA, Van Wet L, Takeuchi H, Van der Ploeg AT, Reuser AJJ (2007) Chemical chaperones improve transport and enhance stability of mutant alphaglucosidases in glycogen storage disease type II. Mol Genet Metab 90: 49-57

Prudencio M, Hart PJ, Borchelt DR, Andersen PM (2009) Variation in aggregation propensities among ALS-associated variants of SOD1: correlation to human disease. Hum Mol Genet 18: 3217-3226

Qin JY, Zhang L, Clift KL, Hulur I, Xiang AP, Ren B-Z, Lahn BT (2010) Systematic Comparison of Constitutive Promoters and the Doxycycline-Inducible Promoter. PLoS ONE 5: e10611

Raimondi A, Mangolini A, Rizzardini M, Tartari S, Massari S, Bendotti C, Francolini M, Borgese N, Cantoni L, Pietrini G (2006) Cell culture models to investigate the selective vulnerability of motoneuronal mitochondria to familial ALS-linked G93ASOD1. Eur J Neurosci 24: 387-399

Rakhit R, Chakrabartty A Structure, folding, and misfolding of $\mathrm{Cu}, \mathrm{Zn}$ superoxide dismutase in amyotrophic lateral sclerosis. Biochimica et Biophysica Acta (BBA) Molecular Basis of Disease 1762: 1025-1037

Ray SS, Nowak RJ, Brown RH, Lansbury PT (2005) Small-molecule-mediated stabilization of familial amyotrophic lateral sclerosis-linked superoxide dismutase mutants against unfolding and aggregation. Proc Natl Acad Sci U S A 102: 3639-3644

Rizzardini M, Lupi M, Mangolini A, Babetto E, Paolo U, Cantoni L (2006) Neurodegeneration induced by complex I inhibition in a cellular model of familial amyotrophic lateral sclerosis. Brain Res Bull 69: 465-474

Rosen DR, Siddique T, Patterson D, Figlewicz DA, Sapp P, Hentati A, Donaldson D, Goto J, O'Regan JP, Deng HX (1993) Mutations in Cu/Zn superoxide dismutase gene are associated with familial amyotrophic lateral sclerosis. Nature 362: 59-62 
Sau D, De Biasi S, Vitellaro-Zuccarello L, Riso P, Guarnieri S, Porrini M, Simeoni S, Crippa V, Onesto E, Palazzolo I, Rusmini P, Bolzoni E, Bendotti C, Poletti A (2007) Mutation of SOD1 in ALS: a gain of a loss of function. Hum Mol Genet 16: 1604-1618

Schmidlin T, Kennedy BK, Daggett V (2009) Structural changes to monomeric CuZn superoxide dismutase caused by the familial amyotrophic lateral sclerosis-associated mutation A4V. Biophys J 97: 1709-1718

Schröder M, Schäfer R, Friedl P (2002) Induction of protein aggregation in an early secretory compartment by elevation of expression level. Biotechnol Bioeng 78: 131-140

Shaw BF, Durazo A, Nersissian AM, Whitelegge JP, Faull KF, Valentine JS (2006) Local unfolding in a destabilized, pathogenic variant of superoxide dismutase 1 observed with H/D exchange and mass spectrometry. J Biol Chem 281: 18167-18176

Shaw BF, Valentine JS (2007) How do ALS-associated mutations in superoxide dismutase 1 promote aggregation of the protein? Trends Biochem Sci 32: 78-85

Tartari S, D'Alessandro G, Babetto E, Rizzardini M, Conforti L, Cantoni L (2009) Adaptation to G93Asuperoxide dismutase 1 in a motor neuron cell line model of amyotrophic lateral sclerosis. FEBS J 276: 2861-2874

Valentine JS, Doucette PA, Zittin Potter S (2005) COPPER-ZINC SUPEROXIDE DISMUTASE AND AMYOTROPHIC LATERAL SCLEROSIS. Annu Rev Biochem 74: 563-593

Waldo GS (2003) Improving protein folding efficiency by directed evolution using the GFP folding reporter. Methods Mol Biol 230: 343-359

Waldo GS, Standish BM, Berendzen J, Terwilliger TC (1999) Rapid protein-folding assay using green fluorescent protein. Nat Biotechnol 17: 691-695

Wang Q, Johnson JL, Agar NY, Agar JN (2008) Protein aggregation and protein instability govern familial amyotrophic lateral sclerosis patient survival. PLoS Biol 6: e170

Watanabe S, Nagano S, Duce J, Kiaei M, Li Q-X, Tucker SM, Tiwari A, Brown Jr RH, Beal MF, Hayward LJ, Culotta VC, Yoshihara S, Sakoda S, Bush AI (2007) Increased 
affinity for copper mediated by cysteine 111 in forms of mutant superoxide dismutase 1 linked to amyotrophic lateral sclerosis. Free Radical Biol Med 42: 1534-1542

Witan H, Kern A, Koziollek-Drechsler I, Wade R, Behl C, Clement AM (2008) Heterodimer formation of wild-type and amyotrophic lateral sclerosis-causing mutant $\mathrm{Cu} / \mathrm{Zn}$-superoxide dismutase induces toxicity independent of protein aggregation. Hum Mol Genet 17: 1373-1385

Wong HE, Kwon I (2011) Xanthene Food Dye, as a Modulator of Alzheimer's Disease Amyloid-beta Peptide Aggregation and the Associated Impaired Neuronal Cell Function. PLOS ONE 6: e 25752

Wong HE, Qi W, Choi H-M, Fernandez EJ, Kwon I (2011) A Safe, Blood-Brain Barrier Permeable Triphenylmethane Dye Inhibits Amyloid- $\beta$ Neurotoxicity by Generating Nontoxic Aggregates. Acs Chemical Neuroscience 2: 645-657

Yumerefendi H, Tarendeau F, Mas PJ, Hart DJ (2010) ESPRIT: an automated, librarybased method for mapping and soluble expression of protein domains from challenging targets. J Struct Biol 172: 66-74. Epub 2010 Mar 2014.

Zhang F, Zhu H (2006a) Intracellular conformational alterations of mutant SOD1 and the implications for fALS-associated SOD1 mutant induced motor neuron cell death. Biochim Biophys Acta 1760: 404-414

Zhang FJ, Zhu HN (2006b) Intracellular conformational alterations of mutant SOD1 and the implications for fALS-associated SOD1 mutant induced motor neuron cell death. Biochimica Et Biophysica Acta-General Subjects 1760: 404-414 